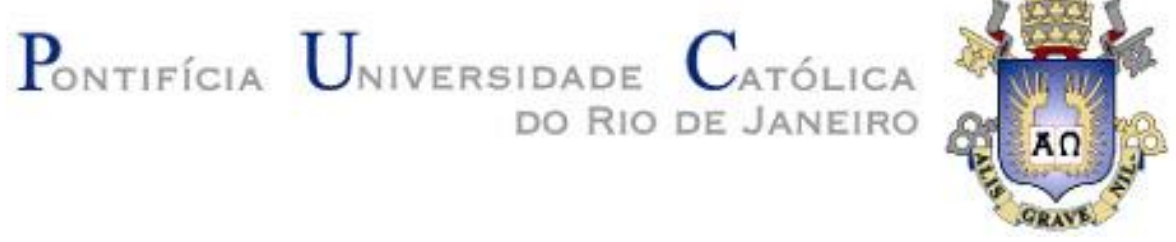

Rodrigo Rocha da Silva

\title{
Avaliação Econômico-Financeira de Contratos de Afretamento de FPSO utilizando Opções Reais
}

Dissertação de Mestrado

Dissertação apresentada como requisito parcial para obtenção do título de Mestre pelo Programa de PósGraduação em Administração de Empresas da PUCRio.

Orientador Prof: Luiz Eduardo Teixeira Brandão

Rio de Janeiro

Abril de 2015 


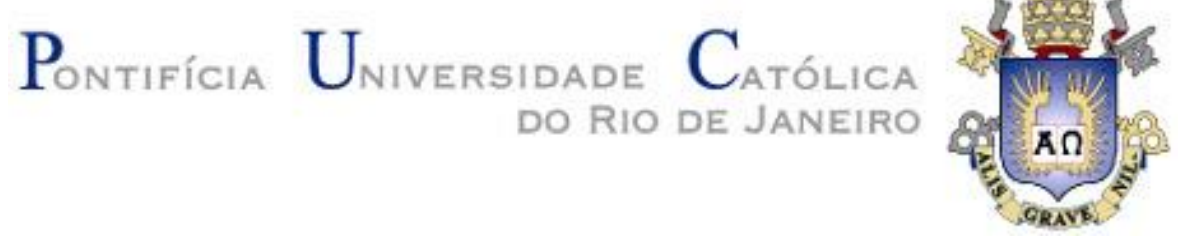

Rodrigo Rocha da Silva

\section{Avaliação Econômico-Financeira de Contratos de Afretamento de FPSO utilizando Opções Reais}

Dissertação apresentada como requisito parcial para obtenção do grau de Mestre pelo Programa de PósGraduação em Administração de Empresas da PUC-Rio. Aprovada pela Comissão Examinadora abaixo assinada.

Prof. Luiz Eduardo Teixeira Brandão Orientador Departamento de Administração - PUC-Rio

Prof. Marcelo Cabus Klotzle Departamento de Administração - PUC-Rio

Prof. Carlos de Lamare Bastian Pinto Grupo IBMEC

Prof. Javier Gutiérrez Castro

Profa. Mônica Herz

Vice-Decana de Pós-Graduação do CCS - PUC-Rio

Rio de Janeiro, 10 de abril de 2015 
Todos os direitos reservados. É proibida a reprodução total ou parcial do trabalho sem autorização da universidade, do autor e do orientador.

\section{Rodrigo Rocha da Silva}

Graduou-se em Administração de Empresa pela Unisuam em 2010. Trabalha com investimentos desde o início de sua carreira profissional. Atualmente trabalha como Especialista em Investimentos na Carta Fabril, tendo passado pela área de Projetos Estruturados da Construtora Andrade Gutierrez e Corporate Finance da KPMG.

Ficha Catalográfica

Silva, Rodrigo Rocha da

Avaliação econômico-financeira de contratos de afretamento de FPSO utilizando opções reais / Rodrigo Rocha da Silva; orientador: Luiz Eduardo Teixeira Brandão. - 2015.

51 f. : il. (color.) ; $30 \mathrm{~cm}$

Dissertação (mestrado) - Pontifícia Universidade Católica do Rio de Janeiro, Departamento de Administração, 2015.

Inclui bibliografia

1. Administração - Teses. 2. Opções reais. 3. Processo competitivo. 4. Avaliação econômico-financeira. 5. FPSO. I. Brandão, Luiz Eduardo Teixeira. II. Pontifícia Universidade Católica do Rio de Janeiro. Departamento de Administração. III. Título. 


\section{Agradecimentos}

Primeiramente gostaria de agredecer a Deus, pois sem ele nada seria possível.

À minha esposa Sara de Moraes, que me apoiou, me incentivando, muitas vezes se sacrificando pelos meus sonhos, essa conquista também é dela.

Às minhas filhas Manuela e Luiza, que apesar de terem menos de um ano de idade, e terem nascido no momento da elaboração desse trabalho me ensinaram uma forma diferente de ver a vida.

Aos meus pais, que me apoiaram, da sua maneira, e me ajudaram a conquistar esse objetivo.

Ao meu orientador Luiz Brandão, que me ensinou o que são opções reais e me orientou de forma excepcional neste trabalho, trazendo sempre boas ideias me ajudando a simplificar minha forma de pensar.

Aos meus colegas do mestrado, cada um com sua história de superação e conquista.

Aos meus companheiros de trabalho da Andrade Gutierrez e da Carta Fabril, sem o apoio deles a conclusão deste trabalho não seria possível.

Aos meus amigos que me ajudaram de forma direta e indireta ao longo do mestrado e na elaboração deste trabalho. 


\section{Resumo}

Silva, Rodrigo Rocha; Brandão, Luiz Eduardo Teixeira. Avaliação Econômico-Financeira de Contratos de Afretamento de FPSO utilizando Opções Reais. Rio de Janeiro, 2015. 51p. Dissertação de Mestrado - Departamento de Administração, Pontifícia Universidade Católica do Rio de Janeiro.

Contratos de afretamento de FPSO, tipicamente contêm cláusulas de extensão de prazo após um número fixo de anos, sendo que o exercício dessas opções de extensão é prerrogativa da empresa de Exploração e Produção (E\&P) que contrata o ativo. Dado que esta flexibilidade gerencial não é capturada pelos métodos tradicionais de avaliação de projetos como o método do Fluxo de Caixa Descontado, um desafio surge: como definir o valor do projeto dado que existem opções de extensão contratual? Neste trabalho foi utilizada a TOR (Teoria de Opções Reais) para analisar o valor das opções sob o ponto de vista do afretador da FPSO, considerando que o exercício destas opções resulta no recebimento, por parte do afretador, de fluxos de caixa adicionais ao final do período fixo de anos estabelecido no contrato. Diferentemente do tratamento padrão de valor de opções encontrado na literatura, neste caso agrega-se valor também ao afretador da FPSO apesar deste estar na posição vendida no contrato. Foram utilizados dois processos estocásticos distintos para a modelagem das incertezas e precificação das opções. O primeiro utilizou como base o MGB (Movimento Geométrico Browniano) e o segundo o MRM (Movimento de Reversão à Média). Os resultados encontrados em ambos os modelos sugerem que a precificação das opções de extensão agrega valor ao contrato e consequentemente pode tornar o afretador da FPSO mais competitivo no processo concorrencial, uma vez que é possível o compartilhamento de parte desse valor adicional com a empresa de E\&P através da redução do valor da taxa de afretamento da FPSO.

\section{Palavras-chave}


Opções reais; processo competitivo; avaliação econômico-financeira; FPSO.

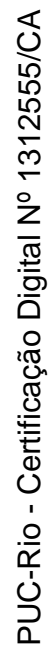




\section{Abstract}

Silva, Rodrigo Rocha; Brandão, Luiz Eduardo Teixeira (Advisor). FPSO Chartering Contracts Valuation using Real Option Approach. Rio de Janeiro, 2015. 51p. MSc. Dissertation - Departamento de Administração, Pontifícia Universidade Católica do Rio de Janeiro.

FPSO contracts tipically include clauses that allow contractual extensions after a fixed period of time. The exercise of these extensions options are the prerogative of the Exploration and Production (E\&P) company that hires the FPSO. This management flexibility is not captured by traditional valuation tools such as the Discounted Cash Flow method, and thus, the challenge is how to define the value of a project given that exist contractual extensions options. In this work we analyse the value of these options from the standpoint of an FPSO chartering firm under the Real Options approach, considering that the exercise of these options result in additional cash flows to the chartering company beyond the original contract term. Differently of traditional results in options valuation found in literature, in this case, value is added also to the chartering firm, even though the firm holds a short position in the options. Two different stochastic processes were used to model project uncertainty and option pricing. The first was based on Geometric Brownian Motion (GMB) and the second in Mean Reverting Processes (MRP). The results in both cases suggest that the valuation of contractual extensions options add value to the project, and thus to the chartering firm, and consequently may improve the competitive position of the FPSO chartering firm in a bid process, as it is possible to share part of this value with E\&P company through a reduction in the cost of the charter.

\section{Keywords}

Real options; competitiveness; Business Valuation; FPSO. 


\section{Sumário}

1 Introdução

2 Referencial Teórico e Revisão de Literatura 15

2.1. Referencial Teórico 15

2.1.1. Fluxo de Caixa Livre 15

2.1.2. Metodologias Tradicionais de Avaliação de Projetos/Empresas 16

2.1.2.1. Valor Presente Líquido (VPL) 16

2.1.2.2. Taxa Interna de Retorno 17

2.1.2.3. Limitações das Metodologias Tradicionais 17

2.1.3. Processos Estocásticos 18

2.1.4. Teoria de Opções Reais 19

2.1.4.1. Movimento Geométrico Browniano (MGB) em Opções Reais 19

2.1.4.2. Movimento de Reversão à Média (MRM) em Opções Reais 21

2.1.4.2.1. Modelo Binomial de Nelson e Ramaswamy (1990) 23

2.1.4.3. Determinação do Modelo 25

2.2. Revisão de Literatura 26

3 Mercado de Petróleo e Gás 28

3.1. Principais características da cadeia offshore 28

3.2. FPSO (Floating, Production, Storage and Offloading) 29

4 Principais características dos contratos de afretamento 32

4.1. Principais características do modelo de contratação 32

5 Metodologia Utilizada $\quad 35$

5.1. Modelo Estocástico 37

5.1.1. Modelagem do Preço do Petróleo através de MGB 38

5.1.2. Modelagem do Preço do Petróleo através do MRM 39

6 Aplicação do modelo em um contrato de afretamento de FPSO 42 
6.1. Avaliação do Projeto Através das Ferramentas Tradicionais: VPL e TIR

6.2. Avaliação utilizando Opções Reais

7 Conclusão

8 Referências Bibliográficas 


\section{Lista de figuras}

Figura 1 - Exemplo Árvore Binomial de Um Passo .............................................. 21

Figura 2 - Cadeia de Produção de Petróleo .......................................................... 28

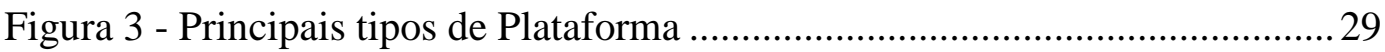

Figura 4 - Processo Competitivo - Contratação FPSO …………............................ 34

Figura 5 - Exemplo Exercício da Opção .............................................................. 36

Figura 6 - Preço Histórico do Petróleo Tipo Brent (Europa) ................................ 37

Figura 7- Fluxo de Definição da taxa diária de afretamento .................................. 42 


\section{Lista de Tabelas}

Tabela 1 - Modelos para Previsão de Preço de Petróleo para Uso em Opções

Reais 18

Tabela 2 - Valores Críticos para o Teste Augmented Dickey-Fuller .................... 26

Tabela 3 - Teste de Raíz Unitária (DF) ............................................................... 38

Tabela 4 - Modelagem Preço do Petróleo - MGB .................................................. 39

Tabela 5 - Modelagem Preço do Petróleo - MRM .................................................. 41

Tabela 6 - Probabilidade de Subida - MRM ......................................................... 41

Tabela 7 - Probabilidade de Descida - MRM ........................................................ 41

Tabela 8 - Fluxo de Caixa Projetado (US\$ Milhões) …......................................... 44

Tabela 9 - Fluxo Adicional - Exercício da Extensão Contratual (1 ano) -

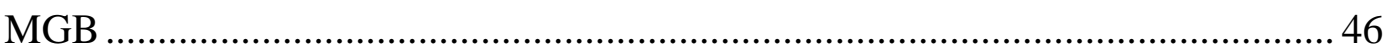

Tabela 10 - Cálculo da Opção de Extensão Contratual (1 ano) - MGB ................ 46

Tabela 11 - Fluxo Adicional - Exercício da Extensão Contratual (5 anos) -

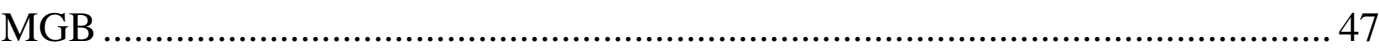

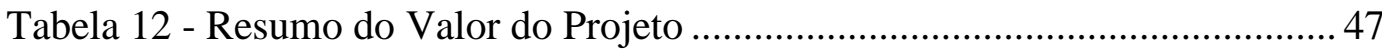

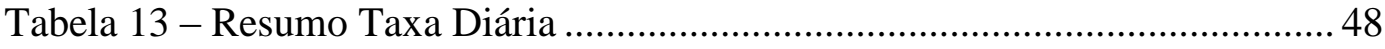




\section{Introdução}

Referências ao petróleo (óleo de pedra) ou, mais precisamente, betume, asfalto ou mesmo piche, podem ser encontradas em escritos que remontam a antiguidade (Rouzaut \& Favennec, 2011).

O petróleo moveu a economia dos principais países desde a sua descoberta e início da exploração comercial. O custo de exploração e produção (E\&P) vem crescendo nas últimas décadas em função da exaustão das reservas existentes e necessidade de busca de novos campos, cujo processo de pesquisa e exploração tem se tornado cada vez mais complexo.

O mercado de petróleo vem passando por mudanças importantes nos últimos anos. Com o advento das novas tecnologias, alta volatilidade dos preços no mercado internacional, capital intensivo envolvido na atividade, e escassez das reservas existentes, as empresas precisam tomar decisões de priorização de investimento de forma mais eficaz.

O processo de descoberta e produção de petróleo envolve basicamente três etapas: exploração, desenvolvimento e produção.

A atividade de exploração é composta do levantamento e processamento de dados exploratórios, sondagem e delimitação do campo. A fase de desenvolvimento consiste na perfuração e completação dos poços de produção, além da instalação dos equipamentos submarinos que conectarão o poço de retirada do óleo à plataforma de exploração e produção. Já a fase de produção, é composta basicamente pelo estudo do reservatório, desenvolvimento da produção e produção.

A atividade de produção no mar (offshore) é realizada através de plataformas de extração e tratamento do petróleo. A escolha do tipo de plataforma depende das características do campo no qual a mesma será utilizada.

Em se tratando de águas profundas, a exploração é realizada basicamente, através de plataformas flutuantes de produção, armazenamento e transferência, chamadas de FPSO (Floating, Production, Storage and Offloading). Esse tipo de 
plataforma é semelhante às tradicionalmente existentes, a diferença é que os módulos que realizam o processo de separação e químico estão sobre uma embarcação, além disso, a plataforma não é fixada no leito do Oceano. Outra característica importante é que o casco é utilizado como tanque de armazenamento, reduzindo assim, a frequência da necessidade de navios aliviadores, utilizados para transportar o petróleo entre a embarcação e a terra.

Um dos dilemas mais comuns enfrentados pelas empresas de E\&P no processo de produção de petróleo é a escolha da modalidade de contratação da FPSO, que pode ser: compra ou afretamento.

No primeiro modelo, a empresa de E\&P contrata uma empresa para realizar o EPC (Engineering, Procurement and Construction), em português: Engenharia, Suprimentos e Construção. Após a construção da FPSO, a empresa de E\&P é responsável pela manutenção e operação da embarcação.

No segundo modelo, a empresa de E\&P define as características e especificações do óleo, do campo e capacidade de produção e armazenamento desejados para a embarcação. Posteriormente, realiza um processo competitivo para a contratação de uma empresa especializada em operação e afretamento de FPSO (afretador da FPSO), cuja responsabilidade será de prestar serviços de construção, operação e manutenção da embarcação ao longo da vida útil do contrato. Nesse modelo, o proprietário da FPSO não é a empresa de E\&P e sim o afretador da FPSO. Outras modalidades de contratação existem, entretanto em número bem reduzido.

A definição da empresa que irá afretar a embarcação obedece alguns critérios, o mais importante é a melhor proposta econômica, cuja medição se dá pela taxa diária (daily rate) de afretamento e operação. $\mathrm{O}$ afretador que oferecer a menor taxa diária, respeitando os requisitos técnicos estabelecidos é escolhido para prestar o serviço.

A taxa diária a ser ofertada no processo concorrencial é, geralmente, calculada com base na projeção de fluxos de caixa futuros gerados pela atividade de construção, operação e manutenção da FPSO. Nesse modelo, são inseridos os investimentos necessários para a construção da embarcação e custos relacionados à operação e manutenção ao longo da vida útil do contrato. Posteriormente, são calculados o Valor Presente Líquido (VPL) e Taxa Interna de Retorno (TIR). 
No momento de apresentação da taxa diária no processo competitivo, a maioria dos contratos prevê que o afretador da FPSO considere extensões contratuais, por exemplo: contrato de 10 anos com 5 opções de extensão anuais pela mesma taxa diária de afretamento.

Essa característica impõe maior complexidade na definição da taxa diária, visto que existem incertezas sobre o fluxo de caixa futuro gerado pela atividade. Em função disso, não é possível capturar as flexibilidades embutidas nos contratos de afretamento através das metodologias tradicionais de avaliação de projetos. Do ponto de vista prático, o afretador da FPSO dá para a empresa de E\&P opções de extensão contratual (call). A diferença em relação às opções tradicionais é que essas opções de extensão agregam valor também para o afretador da FPSO, ou seja, existe o desejo de que a mesma seja exercida contra ele.

Desta forma, o objetivo desse trabalho é analisar sob a ótica do afretador da FPSO, o que a aplicação de opções reais agrega de valor e consequentemente pode ser utilizado como estratégia de flexibilidade na definição da taxa diária de afretamento e, por conseguinte, tornar o afretador mais competitivo no processo concorrencial. Na literatura, não foram encontrados trabalhos que tiveram como base a precificação de contratos de afretamento de FPSO sob a ótica das empresas de afretamento. 


\section{2 Referencial Teórico e Revisão de Literatura}

\section{1. Referencial Teórico}

As metodologias tradicionalmente utilizadas para a avaliação econômicofinanceira de investimentos se baseiam na utilização de fluxos de caixa futuros para sua aplicação. As regras do VPL (Valor Presente Líquido) e TIR (Taxa Interna de Retorno) são amplamente difundidas e aplicadas no campo das finanças empresariais (Brealey, Myers, \& Allen, 2011).

As metodologias tradicionais possuem algumas fragilidades, pois não consideram as flexibilidades envolvidas na atividade empresarial. Nesse sentido, com o objetivo de tentar solucionar essa deficiência, surgiu a chamada Teoria de Opções Reais (TOR).

Neste capítulo, serão descritas as principais ferramentas de avaliação de projetos existentes, suas limitações, bem como as principais ferramentas e parâmetros que precisam ser definidos para a utilização de Opções Reais.

\subsection{1.}

\section{Fluxo de Caixa Livre}

A base para todas as teorias de avaliação de projetos mencionadas neste trabalho é o Fluxo de Caixa Livre.

O fluxo de caixa livre reflete o resultado da empresa/projeto no período, considerando as receitas provenientes da atividade empresarial e subtraídos os custos, despesas, impostos, gastos de capital, depreciação, amortizações e demais itens ajustados. Adicionalmente, é incluída a variação da necessidade de capital de giro no período.

Os Gastos de Capital (CapEx - Capital Expenditure) referem-se aos investimentos na compra e, quando aplicável, manutenção de ativos da empresa. São investimentos necessários para o exercício da atividade empresarial. 
$\mathrm{Na}$ sua forma tradicional, o capital de giro líquido, muitas vezes designado simplesmente como capital de giro, é a diferença entre o ativo circulante e o passivo circulante (Damodaran, 2002). Como geralmente no primeiro ano de vida da empresa é realizado um investimento em ativos circulantes, o valor da necessidade de capital de giro é maior nesse período. A partir do segundo ano, a tendência é que a necessidade de capital de giro seja inferior.

O principal objetivo do fluxo de caixa livre é mostrar a capacidade que a empresa/projeto tem de gerar valor, a quantidade de caixa livre que poderá ser revertida para o acionista e/ou detentores de dívida.

\subsection{2.}

\section{Metodologias Tradicionais de Avaliação de Projetos/Empresas}

\subsubsection{1.}

\section{Valor Presente Líquido (VPL)}

Para o cálculo do VPL é necessário que seja realizada a projeção dos resultados futuros do projeto/empresa (Fluxo de Caixa Livre), em seguida desconta-se cada fluxo de caixa livre a valor presente por uma taxa de desconto que reflita o custo de oportunidade do investidor. Do ponto de vista prático, se aceita projetos cujo VPL seja positivo, ou seja, projetos cujo VPL agregue valor para o acionista.

A regra do VPL satisfaz muitas das condições colocadas para uma boa regra de tomada de decisão sobre investimento (Damodaran, 2002). Entretanto, como é uma metodologia estática, ou seja, não incorpora flexibilidade inerente da atividade empresarial, não captura ganhos referentes às opções embutidas no projeto.

O VPL pode ser calculado através da seguinte fórmula:

$$
V P L=-I+\sum_{t=1}^{n} \frac{F C t}{(1+i)^{t}}
$$

Onde:

$F C t=$ Fluxo de caixa livre do período $\mathrm{t}$ 
$i=$ Taxa de Desconto

$n=$ Vida do Projeto

$I=$ Investimento Inicial

\subsubsection{2.}

\section{Taxa Interna de Retorno}

A taxa interna de retorno é definida como a taxa de desconto que iguala o valor presente das entradas e saídas de caixa ao investimento inicial referente a um projeto (Gitman, 1997).

Como resultado, de forma geral, se a TIR for superior à taxa de desconto do projeto, o VPL será positivo e a conclusão será a aceitação do projeto.

A TIR pode ser calculada através da seguinte fórmula:

$$
T I R=-I+\sum_{t=0}^{n} \frac{F C t}{(1+i)^{t}}=0
$$

Uma das premissas para a utilização da TIR é que exista pelo menos um fluxo de caixa negativo no início do período do projeto/empresa. Quando se avalia empresas em estágio operacional cuja geração de caixa é toda positiva, a utilização da TIR não é possível.

\subsubsection{3.}

\section{Limitações das Metodologias Tradicionais}

As teorias tradicionais de avaliação de projetos são estáticas, ou seja, não incorporam às flexibilidades gerenciais que são intrínsecas à atividade empresarial. Essas metodologias assumem que a empresa mantém os ativos de forma passiva, não incorporam a possibilidade de adiamento/antecipação dos investimentos em andamento e outras flexibilidades gerenciais: expansão, mudança de mix de produção, etc.

A natureza de qualquer projeto possui incertezas sob a real realização dos fluxos de caixa futuro projetados, isso impacta diretamente o valor e retorno dos negócios, além da decisão a respeito da continuidade dos investimentos. Projetos 
com VPL estáticos negativo podem se tornar atrativos com a incorporação de opções.

Com o objetivo de tentar solucionar esse problema na avaliação dos projetos, surgiu a TOR, cuja aplicabilidade possibilita a avaliação das flexibilidades intrínsecas da atividade empresarial.

\subsection{3.}

\section{Processos Estocásticos}

Um processo estocástico representa uma variável que muda randomicamente ao longo do tempo, pelo menos parcialmente, e pode ser classificada como estacionária, quando os parâmetros estatísticos são constantes ao longo de um determinado período ou não-estacionária (Dixit \& Pindyck, 1994).

A escolha do processo estocástico que reflete melhor o comportamento da variável de incerteza é de fundamental importância para a precificação de opções.

Um dos processos estocásticos comumente utilizados para a modelagem de ativos reais e financeiros é o movimento geométrico browniano, que assume um processo de difusão lognormal onde a variância aumenta linearmente com o tempo. Outro processo que pode ser utilizado para modelar preços de algumas commodities é o modelo de reversão à média (MRM), cuja aplicabilidade nesse tipo de ativo se dá pelo fato de terem preços de equilíbrio de longo prazo.

Dias (2005) sumariza as alternativas de processos estocásticos para a modelagem de preços de petróleo em três categorias, conforme Tabela 1:

Tabela 1 - Modelos para Previsão de Preço de Petróleo para Uso em Opções Reais

\begin{tabular}{|c|c|c|}
\hline Tipo de Modelo Estocástico & Nome do Modelo & Referências \\
\hline Modelo Imprevisível & $\begin{array}{l}\text { Movimento geométrico Browniano } \\
\text { (MGB) }\end{array}$ & Paddock, Siegel \& Smith (1988) \\
\hline Modelo Previsível & Reversão à Média Puro (MRM) & Schwartz (1997, modelo 1) \\
\hline \multirow{3}{*}{ Modelos Mais Realistas } & Modelo de Dois ou Três Fatores & $\begin{array}{l}\text { Gibson \& Schwartz (1990) e } \\
\text { Schwartz (modelo } 2 \text { e 3) }\end{array}$ \\
\hline & $\begin{array}{l}\text { MRM com Preço de Equilíbrio } \\
\text { Estocástico }\end{array}$ & $\begin{array}{c}\text { Pyndyck (1999) e Baker, Mayfield \& } \\
\text { Parsons (1998) }\end{array}$ \\
\hline & MRM com com Saltos & Dias \& Rocha (1998) \\
\hline
\end{tabular}

Dias (2005) 
Neste trabalho serão abordados somente os modelos imprevisível e previsível.

\subsection{4.}

\section{Teoria de Opções Reais}

A Teoria de Opções Reais foi originalmente concebida com base na teoria de precificação de opções financeiras.

As opções financeiras podem ser divididas basicamente em dois tipos: Opções Americanas e Opções Europeias. De acordo com (Merton, 1973), uma opção de compra americana dá o direito para o seu proprietário de comprar um ativo por um preço de exercício estabelecido até uma data definida. Uma opção do tipo europeia tem os mesmos termos de uma opção americana com exceção de que o exercício somente pode ser realizado no último dia do contrato (Merton, 1973).

Os precursores do modelo de precificação de opções foram Fisher Black, Myron Scholes e posteriormente Merton, que criaram o modelo BSM (Black, Scholes e Merton), que assume como premissa principal que o ativo base segue um movimento geométrico browniano (MGB), esse modelo foi concebido para a precificação de compra opções do tipo europeias.

\subsubsection{1.}

\section{Movimento Geométrico Browniano (MGB) em Opções Reais}

O MGB é um caso particular do Processo de Ito, geralmente utilizado para modelar preço de ações, taxa de juros, preço de produtos e outras variáveis financeiras e econômicas (Dixit \& Pindyck, 1994). É o modelo mais utilizado visto que assume a premissa que a variável segue uma distribuição normal onde os retornos e a volatilidade do processo são constantes, o que representa a característica de boa parte dos ativos negociados.

O MGB em tempo contínuo pode ser descrito da seguinte forma:

$$
d S=\mu S d t+\sigma S d z
$$


Onde:

$S=$ Valor do ativo

$\mu=$ Taxa de retorno esperada

$\sigma=$ Volatilidade do valor do ativo

$d t=$ Variação do tempo

$d z=$ Variável estocástica

A primeira parcela $\mu S d t$ representa o crescimento proporcional com taxa $\mu$. A segunda $\sigma S d z$ representa o crescimento aleatório proporcional, considerando uma distribuição normal e com desvio padrão $\sigma$.

Infelizmente, a ferramenta matemática empregada no modelo BSM é avançada demais e tem a tendência não mostrar a base econômica (Cox, Ross, \& Rubinstein, 1979). Nesse sentido, Cox, Ross e Rubinstein desenvolveram em 1979, um modelo discreto cujos resultados convergem com o movimento geométrico browniano. Esse modelo é demonstrado através de uma árvore binomial, também conhecida como árvore binomial CRR.

A árvore binomial é construída através da multiplicação do preço do ativo $(S)$ por dois fatores $u$ e $d$. Ao se multiplicar o valor base por $u$, encontra-se o valor superior do nó da árvore binomial, já na multiplicação do valor por $d$, encontra-se o nó inferior da árvore. No caso da árvore binomial CRR, $u$ e $d$ são definidos de forma que, no limite $(\Delta t \rightarrow 0)$, os valores do ativo base na maturidade formem uma distribuição lognormal.

Para a aplicação do MGB em opções reais é necessária a definição da probabilidade $p$ de subida e descida da árvore binomial. Essa probabilidade é utilizada para trazer os valores da árvore binomial à valor presente.

Os parâmetros $u, d$ e $p$ são definidos da seguinte forma, sendo $p$ a probabilidade neutra ao risco:

$$
\begin{aligned}
& \mu=e^{\sigma \sqrt{\Delta t}} \\
& d=e^{-\sigma \sqrt{\Delta t}}=1 / u \\
& p^{+}=\frac{1+r f-d}{u-d}
\end{aligned}
$$


Onde:

$\sigma=$ Volatilidade do valor do ativo

$\Delta t=$ Intervalo de tempo

$r f=$ taxa livre de risco

Figura 1 mostra o exemplo da construção de uma árvore binomial de um passo:

\section{Figura 1 - Exemplo Árvore Binomial de Um Passo}

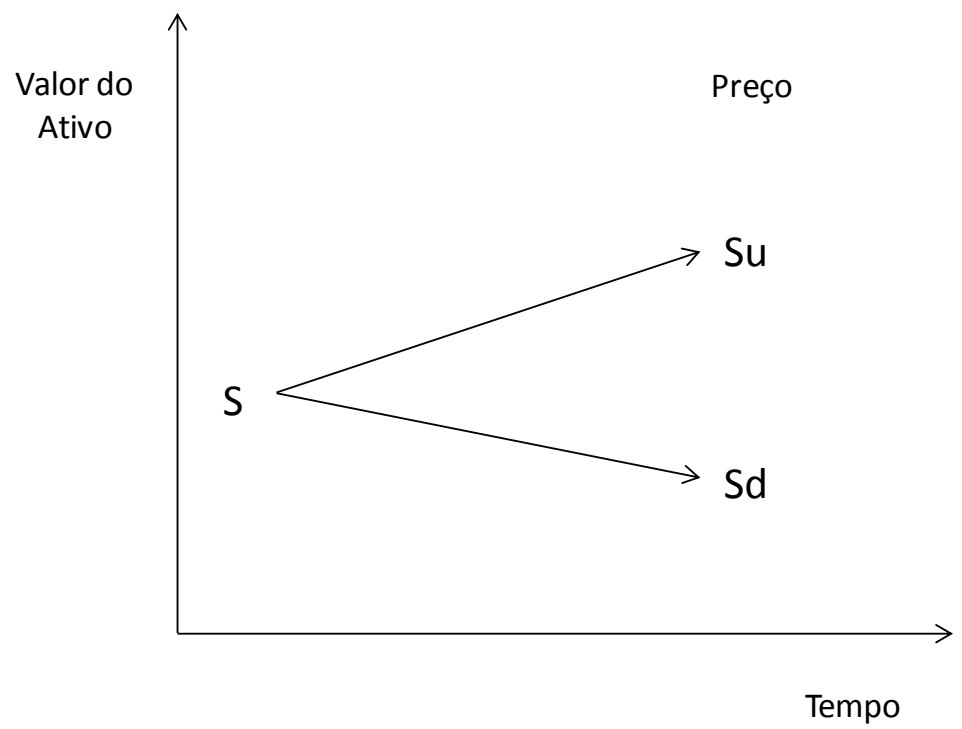

Outra característica importante do modelo CRR é a possibilidade de precificação de opções americanas, cujo exercício pode ser realizado a qualquer momento nos nós da árvore binomial.

\subsubsection{2.}

\section{Movimento de Reversão à Média (MRM) em Opções Reais}

O MRM é um processo de Markov no qual o sentido e a intensidade do desvio são dependentes do preço corrente que deve reverter a uma média de equilíbrio de mercado que é assumida como sendo o preço médio de longo prazo.

O processo é utilizado para a precificação de opções em que o preço do ativo cuja variável de incerteza reverte à média de longo prazo. Dixit and Pindyck (1994) mostraram que o preço de algumas commodities tende a reverter à média em função dos custos marginais de produção no longo prazo, apesar das flutuações no curto prazo. Bastian (2009) argumenta que a lógica por traz de um movimento de reversão à média vem da microeconomia: quando os preços estão 
deprimidos (ou abaixo da sua média histórica) a demanda pelo produto tende a aumentar o que faz com que o preço de equilíbrio se restabeleça.

O MRM na sua forma mais simples é um processo aritmético de OrnsteinUhlenbeck, definido através da seguinte equação:

$$
d x_{t}=\eta\left(\bar{x}-x_{t}\right) d t+\sigma d z_{t}
$$

Onde:

$x_{t}=$ é o $\ln \left(\operatorname{logarítimo~neperiano)~da~variável~modelada~} S_{t}\right.$

$\eta=\mathrm{a}$ velocidade de reversão à média

$\bar{x}=$ a média de longo prazo para a qual $x_{t}$ reverte

$\sigma=$ volatilidade do processo

$d z=$ Variável estocástica $=\varepsilon \sqrt{d t}$

Dixit and Pindyck (1994) mostraram que a variável $x_{t}$ tem uma distribuição normal e cuja média e variância podem ser descritas através das seguintes equações, respectivamente:

$$
\begin{aligned}
& E\left[x_{t}\right]=\bar{x}+\left(x_{0}-\bar{x}\right) e^{-n t} \\
& \operatorname{Var}\left[x_{t}\right]=\frac{\sigma^{2}}{2 \eta}\left(1-e^{-2 n t}\right)
\end{aligned}
$$

A utilização do MRM requer a estimação de parâmetros adicionais que não são necessários no caso do MGB. A determinação desses parâmetros é obtida da seguinte forma:

Primeiramente escrevemos o processo a partir da equação (8) em termos do intervalo temporal discreto:

$$
\begin{aligned}
& x_{t}=\bar{x}\left(1-e^{-\eta \Delta t}\right)+e^{-\eta \Delta t} x_{t-1} \\
& x_{t}=\bar{x}+\left(x_{t-1}-\bar{x}\right) e^{-\eta \Delta t} \\
& x_{t}-x_{t-1}=\bar{x}\left(1-e^{-\eta \Delta t}\right)+\left(e^{-\eta \Delta t}-1\right) x_{t-1}
\end{aligned}
$$

Se escrevermos a equação na forma: 


$$
x_{t}-x_{t-1}=a+(b-1) x_{t-1}+\varepsilon_{t}
$$

Onde $\varepsilon_{t}$ representa o erro da série.

Podemos estimar os parâmetros do processo fazendo uma regressão linear sobre as séries $x_{t}$. A partir dos estimadores obtidos através da regressão linear, podemos calcular os parâmetros a partir da equação (11).

Temos $b-1=e^{-\eta \Delta t}-1, \eta=-\ln (b) / \Delta t$ e $\bar{x}=-\frac{a}{(b-1)}$.

\subsubsection{1.}

Modelo Binomial de Nelson e Ramaswamy (1990)

Existem diversos modelos para o apreçamento de opções reais que apresentam características de MRM. O modelo censurado de Nelson e Ramaswamy (1990) pode ser utilizado em uma ampla variedade de condições, em função disso foi utilizado neste trabalho. O modelo é uma sequência binomial simples de $n$ períodos de duração $\Delta t$, com horizonte de tempo $T: T=n \Delta t$, que permite que a árvore binomial recombinante possa ser construída.

A equação diferencial geral para o processo estocástico é dada pela equação abaixo:

$$
d x=\mu(x, t) d t+\sigma(x, t) d z
$$

Os parâmetros principais para a montagem da árvore binomial podem ser calculados através das seguintes equações:

(Movimento de subida) $x_{t}^{+} \equiv x+\sqrt{\Delta t \sigma}(x, t)$

(Movimento de descida) $x_{t}^{-} \equiv x-\sqrt{\Delta t \sigma}(x, t)$

(Probabilidade de subida) $p_{t} \equiv 1 / 2+1 / 2 \sqrt{\Delta t} \frac{\alpha(x, t)}{\sigma(x, t)}$

(Probabilidade de descida) $1-p_{t}$ 
No modelo, a probabilidade $p_{t}$ pode assumir valores negativos ou superiores a 1 . Os autores sugerem censurar os valores de $p_{t}$ se os mesmos forem superior a 1 ou inferior à 0 , da seguinte forma:

$$
\begin{array}{ll}
\frac{1}{2}+\frac{1}{2} \frac{\alpha(x, t)}{\sigma(x, t)} \sqrt{\Delta t} & \text { se } p \geq 0 \text { e } p_{t} \leq 1 \\
0 & \text { se } p_{t} \geq 0, p_{t} \text { é censurado } \\
1 & \text { se } p_{t} \geq 1, p_{t} \text { é censurado }
\end{array}
$$

Se compararmos a equação com a equação (7) temos:

$$
\begin{aligned}
& \alpha(x, t)=\eta\left(\bar{x}-x_{t}\right), \mathrm{e} \\
& \sigma(x, t)=\sigma
\end{aligned}
$$

Ainda podemos ter valores negativos ou superiores a 1 nos seguintes casos:

Se $\left(\bar{x}-x_{t}\right) \sqrt{\Delta t}>\sigma$, então $p_{x t}>1$

Se $\left(\bar{x}-x_{t}\right) \sqrt{\Delta t}<-\sigma$, então $p_{x t}<0$

Desta forma, o valor de $p_{t}$ precisa ser censurado conforme o esquema a seguir:

$$
\begin{array}{ll}
\frac{1}{2}+\frac{\eta\left(\bar{x}-x_{t}\right) \sqrt{\Delta t}}{2 \sigma} & \text { se } p \geq 0 \text { e } p_{t} \leq 1 \\
0 & \text { se } p_{t} \geq 0, p_{t} \text { é censurado } \\
1 & \text { se } p_{t} \geq 1, p_{t} \text { é censurado }
\end{array}
$$

O valor de $p_{x t}$ :

$$
p_{x t}=\max \left(0, \min \left(1, \frac{1}{2}+\frac{1}{2} \frac{\eta\left(\bar{x}-x_{t}\right)}{\sigma} \sqrt{\Delta t}\right)\right)
$$


Cada probabilidade de movimento ascendente $p_{t}$ irá depender de $x_{t}$, gerando uma árvore de probabilidades de subida $p_{x t}$ e outra de descida.

Após montagem da árvore binomial, é necessário que se desconte o fluxo pela taxa livre de riscos levando em consideração o prêmio de risco do processo $x_{t}$ (Dixit \& Pindyck, 1994): $\lambda_{t}$.

O ajuste para transformar um MRM em neutro a risco, como se faz necessário nos casos de apreçamento de opções, se dá na sua média de longo prazo $\bar{x}$, penalizando esta pelo prêmio de risco normalizado do processo: $\bar{x}-\lambda_{x} / \eta$ (Bastian-Pinto \& Brandão, 2007; Dixit \& Pindyck, 1994),

$$
p_{x_{t}}=\max \left(0, \min \left(1, \frac{1}{2}+\frac{1}{2} \frac{\eta\left[\left(\bar{x}-\lambda_{x} / \eta\right)-x\right]}{\sigma} \sqrt{\Delta t}\right)\right)
$$

\subsubsection{3. \\ Determinação do Modelo}

Dado que processos estocásticos distintos podem ser utilizados para modelar as variáveis de incerteza, existem algumas metodologias para a definição de qual seria o processo mais apropriado.

Um dos testes estatísticos que pode ser utilizado para verificar a característica da série é o chamado teste de raiz unitária. Esse teste pode ser utilizado para identificar se o preço histórico do ativo possui características de MGB. O teste de raiz unitária mais utilizado é o teste Augmented Dickey-Fuller.

$\mathrm{O}$ teste faz uma regressão sobre a equação: $x_{t}=a+b x_{t-1}+\varepsilon_{t}$, verificando se a hipótese nula que $b=l$ é rejeitada.

A forma mais comum de se escrever a equação é a seguinte:

$$
x_{t}-x_{t-1}=a+(b-1) x_{t-1}+\varepsilon_{t}
$$

O $H_{0}$ (hipótese nula) é que a série tem raiz unitária. Se o valor encontrado for superior ao valor crítico, a hipótese nula é rejeitada, o que significa que a série é não-estacionária, e não apresenta características de MGB. 
Como o teste estatístico não segue uma distribuição $t$ usual, visto que a premissa é de não estacionaridade, a série segue uma distribuição não padrão. Em função disso, o valor encontrado no teste deve ser comparado à Tabela 2 (Dickey \& Fuller, 1981):

Tabela 2 - Valores Críticos para o Teste Augmented Dickey-Fuller

\begin{tabular}{lccc}
\hline Nível de Significância & $10 \%$ & $5 \%$ & $1 \%$ \\
\hline Valor Crítico sem tendência temporal & $-2,57$ & $-2,86$ & $-3,43$ \\
Valor Crítico com tendência temporal & $-3,12$ & $-3,41$ & $-3,96$ \\
\hline
\end{tabular}

Para mais informações sobre o teste de raiz unitária ver (Brooks, 2008).

\section{2.}

\section{Revisão de Literatura}

Os contratos de afretamento de FPSOs são similares a contratos de leasing, onde o afretador da FPSO é o responsável pela operação e proprietário da embarcação. O contratante é a empresa de E\&P que usufrui dos serviços por determinado tempo. Possuem também características de ativos que pagam dividendos fixos, pois o valor da FPSO é reduzido a medida que a embarcação é depreciada.

Trigeorgis (1996) avaliou opções embutidas em contratos de leasing operacional através de Contingent Claims. Myers, Dill, and Bautista (1976) avaliaram contratos de leasing financeiro utilizando a metodologia do "Valor Presente Ajustado" sob a ótica de leasing versus captação de empréstimos.

Geske and Johnson (1984) provaram que o modelo binomial é computacionalmente eficiente e concluíram que "a aproximação binomial parece dominar todas as diferenças finitas quando não existem payouts ou um pequeno número de opções são precificadas". Quando são avaliadas opções de ações que pagam dividendos fixos (ao contrário de taxas fixas de dividendos), entretanto, a eficiência do modelo binomial é deteriorada (Schroder, 1988).

Geske and Johnson (1984) derivaram uma fórmula analítica para a precificação de opções americanas com pagamento de dividendos fixos e sem 
pagamento de dividendos. Os autores consideraram a opção como uma soma de opções compostas exercíveis de forma discreta em cada ponto do tempo.

Roll (1977) derivou uma fórmula analítica para a precificação de opções americanas de ações com dividendos fixos antes da expiração através demonstrando que o payoff da opção pode ser replicado através da montagem de dois portfólios de duas opções europeias e uma opção composta.

Schroder (1988) utilizou uma adaptação ao modelo binomial para a precificação de ativos com pagamento de dividendos fixos. Neste modelo, o autor argumenta que em função da premissa que assume que o preço das ações antes da distribuição de dividendos segue uma distribuição lognormal, o preço da ação que paga dividendos pode ser dividido em duas partes. A primeira parte sem risco representa o valor presente de todos os dividendos que serão pagos durante o período de exercício da opção, já a parte com risco, representa o valor remanescente líquido da empresa.

Duarte (2012) analisou a precificação de contratos de afretamento de FPSOs, sondas, e navios aliviadores sob a ótica da empresa de E\&P, utilizando modelos de precificação de opções analogas aos ativos que pagam dividendos fixos.

Na revisão de literatura, não foram encontrados trabalhos que tiveram como base a precificação de contratos de afretamento de FPSO sob a ótica da empresa de afretamento. 


\section{3 \\ Mercado de Petróleo e Gás}

3.1.

Principais características da cadeia offshore

O processo de produção de petróleo é subdividido em três grandes etapas: exploração, desenvolvimento e produção:

Figura 2 - Cadeia de Produção de Petróleo

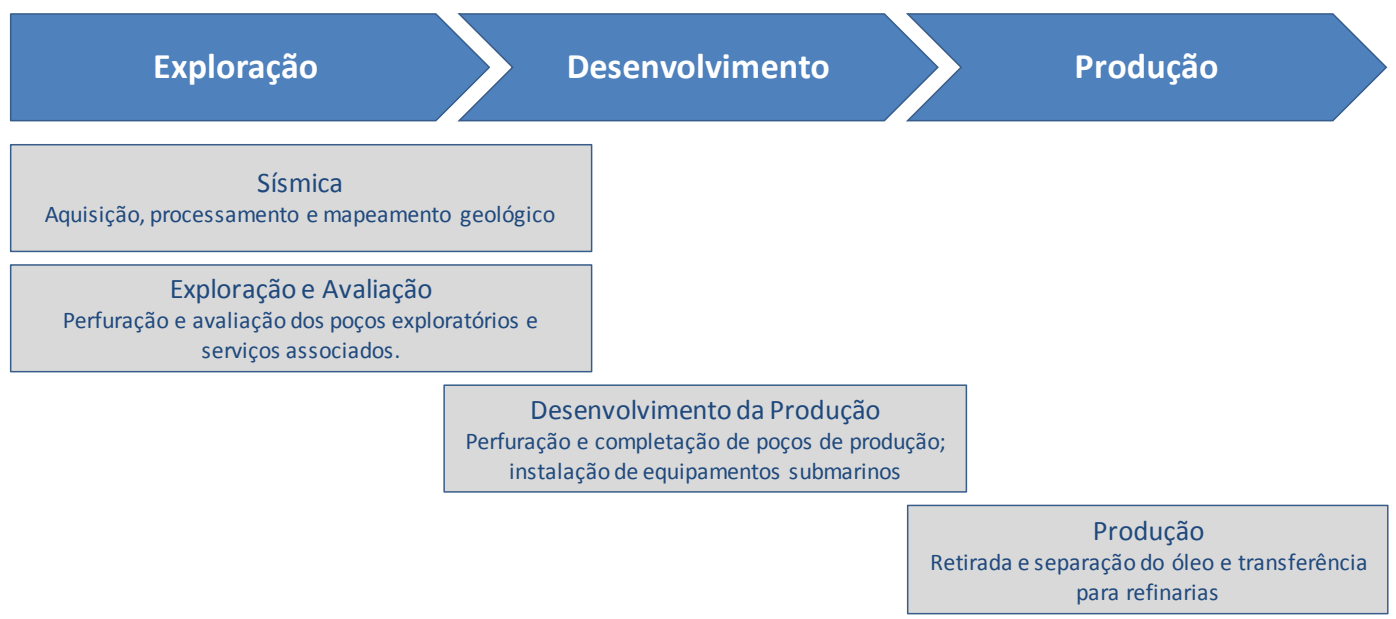

Elaborado pelo Autor

A etapa de exploração é subdividida em duas fases: sísmica e exploração/avaliação. Na primeira é realizado o mapeamento geológico que consiste no estudo das rochas sedimentares, a estratigrafia (organização no tempo e espaço), geologia estrutural (estudo das deformações e fraturas) e geoquímica orgânica (potencial das rochas produzirem óleo). Na segunda fase, são utilizadas sondas de perfuração para medir se efetivamente existe óleo e quais sãos as principais características químicas. Os contratos de locação de equipamentos de perfuração possuem características semelhantes aos das FPSOs, a diferença é que esses equipamentos possuem mais flexibilidade de utilização em diferentes tipos de poços, sendo assim, possuem um mercado secundário ativo para esses equipamentos. 
O processo de desenvolvimento engloba a instalação de toda a estrutura de equipamentos submarinos no leito do oceano.

O processo de produção efetivo se inicia com a conexão da plataforma de produção aos equipamentos submarinos e produção do óleo.

\section{2.}

\section{FPSO (Floating, Production, Storage and Offloading)}

A FPSO é um dos diferentes tipos de plataforma flutuante mais utilizada na indústria de petróleo e gás para produção, armazenamento, e escoamento de petróleo.

\section{Figura 3 - Principais tipos de Plataforma}

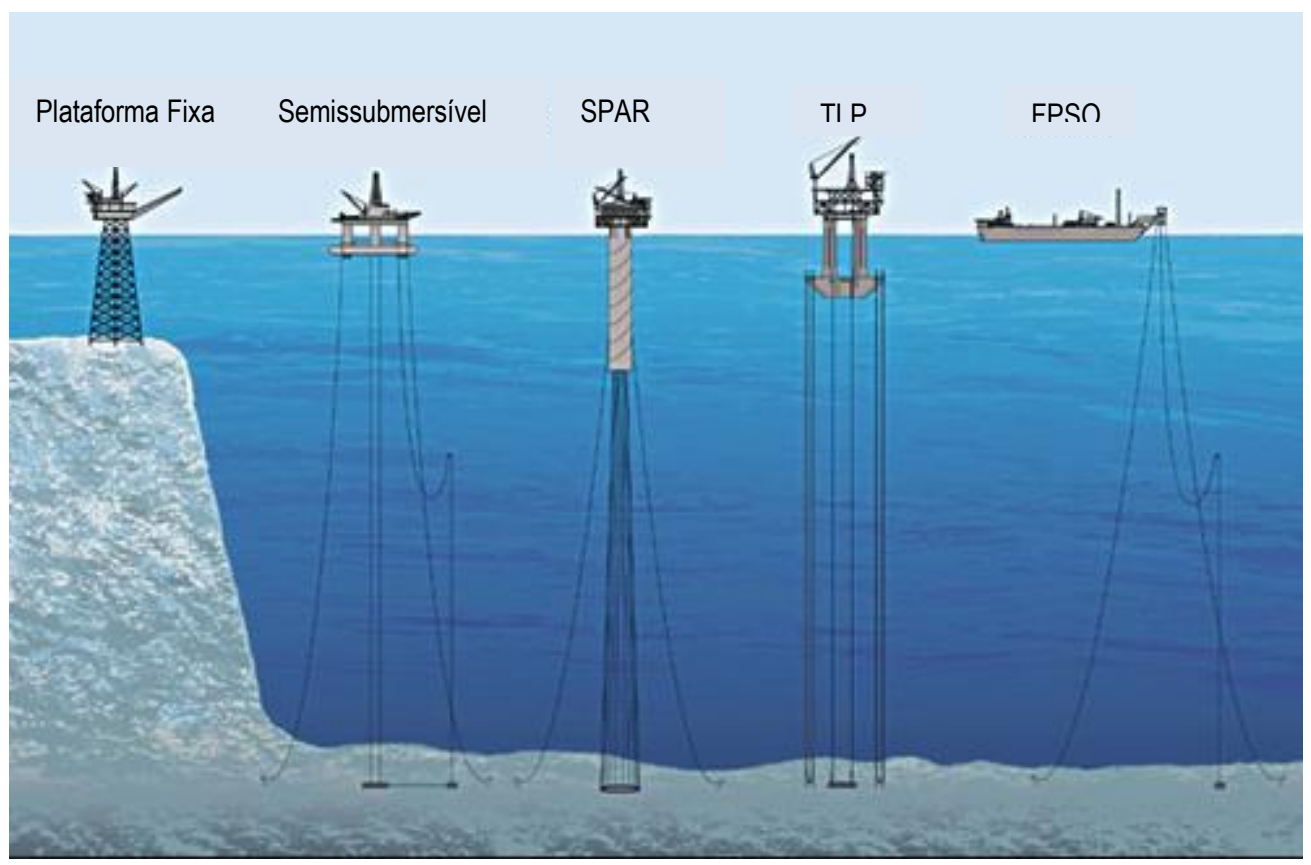

Fonte: oilrigdrillings.com

As FPSOs são utilizadas na produção de petróleo offshore, principalmente em águas profundas.

De acordo com (Catherine, 2011), as principais características que diferenciam a FPSO dos demais tipos de plataforma são:

- Atracação: A FPSO pode ser ancorada em profundidades variadas. 
- Armazenamento de óleo - O casco da FPSO possui amplos tanques onde o petróleo tratado é armazenado até que os navios de apoio realizem o processo de descarga. Essa característica permite a exploração de forma eficaz de campos cuja distância da terra seja muito grande.

- Ampla área para cargas e módulos de produção - O amplo comprimento do deck principal oferece mais espaço que outros tipos de plataforma. Isso significa flexibilidade no processo de produção. Inicialmente o deck pode não estar totalmente ocupado, porém, módulos e equipamentos podem ser agregados com o objetivo de incrementar a capacidade produtiva da embarcação.

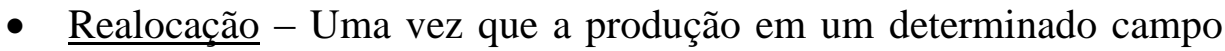
se exauriu, a FPSO pode ser realocada em outros campos mediante a realização de modificações visando a adequação as características de óleo diferentes. Essa modificação não é tão simples, entretanto, é muito realizada na indústria atualmente.

Lombardo (2003) descreve as seguintes etapas básicas do processo de instalação e funcionamento de uma FPSO:

- Atracação na área - Posteriormente à construção e testes, a FPSO é mobilizada no campo. A embarcação é posicionada na área através de sofisticados sistemas de ancoragem que garantem a sua estabilidade. O sistema de ancoragem permite que a FPSO gire livremente em resposta ao movimento do oceano e mudanças no clima.

- Recuperação do Petróleo - A FPSO recupera o petróleo dos campos através de poços localizados no leito do oceano. A infraestrutura necessária para o desenvolvimento do campo inclui os equipamentos de produção e outros itens cuja instalação é de responsabilidade da empresa de E\&P.

O fluído sem tratamento é retirado dos poços através de: 
i. equipamentos instalados no leito do oceano;

ii. um manifold que conecta os vários poços a um tubo flexível;

e

iii. tubos flexíveis que conectam a linha ao FPSO na superfície.

O fluído retirado dos poços é composto de uma substância trifásica de: petróleo cru, água e gás. Após separação das substâncias os fluídos são tratados de forma isolada. O petróleo é estabilizado em uma composição química comercializável, e posteriormente armazenado nos tanques da FPSO. O gás é desidratado, recomprimido e posteriormente queimado, exportado, reinjetado ou utilizado para gerar energia para a FPSO. A água resultante do processo de separação é tratada e descartada ou reinjetada nos poços.

- Petróleo armazenado - O petróleo estabilizado é descarregado através de navios aliviadores em intervalos regulares. 


\section{Principais características dos contratos de afretamento}

\section{1. Principais características do modelo de contratação}

A descrição das principais características desse tipo de contrato neste trabalho é resultado da experiência do autor, sendo sua descrição fundamental para entendimento do trabalho. As informações foram baseadas em casos reais, entretanto não devem ser consideradas como regras desse tipo de contratação, podendo ser modificadas de acordo com a necessidade dos contratantes.

O processo de contratação de uma FPSO no modelo de afretamento é complexo e extenso. A empresa de E\&P, geralmente cria um caderno com as principais características técnicas da embarcação (capacidade de produção, vida útil, etc.), bem como as questões contratuais envolvidas no processo.

No Brasil, o contrato é subdividido em duas partes: contrato de afretamento e contrato de prestação de serviços. Essa subdivisão existe para fins de planejamento tributário, visto que a legislação brasileira permite que o contrato de afretamento seja assinado com empresas com sede no exterior, reduzindo assim a carga tributária do contrato. É importante destacar que um contrato não tem eficácia jurídica sem o outro.

O objetivo do contrato é o afretamento e prestação de serviços de recebimento, processamento, e armazenamento de petróleo a bordo da FPSO, além da injeção de água e transferência de petróleo para navios aliviadores.

O prazo dos contratos variam entre 5 e 20 anos, com opções de compra e/ou extensão contratual detidas pelas empresas de E\&P ao longo do período contratual. Um contrato de 20 anos pode possui opções de compra que podem ou não ser exercidas ao final do $5^{\circ}, 10^{\circ}, 15^{\circ}$ e $20^{\circ}$ anos.

A receita do operador da FPSO é definida através da multiplicação da taxa diária pelos dias de operação da embarcação. A taxa diária é subdividida em: taxa de operação e taxa de afretamento (bareboat). Além dessas receitas, existem 
algumas outras que possuem características extraordinárias que merecem menção neste trabalho: taxa de mobilização, taxa de disponibilidade e taxa de espera.

- Taxa de operacão - é devida quando a empresa de E\&P emite o aceite final da embarcação. É referente à remuneração em $\mathrm{R} \$$ (reais) pela prestação dos serviços de operação da FPSO.

- $\quad$ Taxa de afretamento - é devida quando a empresa de E\&P emite o aceite final da embarcação. É referente à remuneração, usualmente, em dólares americanos (USD) pelo afretamento da FPSO para a empresa de E\&P.

- Taxa de mobilização - é referente à remuneração devida em função dos custos de mobilização da FPSO, tais como: custo de reboque, certificação, seguros, inspeções legais, combustível, tripulação e outros.

- Taxa de disponibilidade - é devida quando a empresa de E\&P não cumpre o prazo indicado em contrato para início do teste de aprovação da embarcação. Essa taxa é, em alguns casos, correspondente a $90 \%$ da taxa de afretamento.

- Taxa de espera - é devida quando a empresa de E\&P interrompe a produção em função de questões não imputáveis ao operador da FPSO, em alguns casos, corresponde a $95 \%$ da taxa de afretamento.

Na maioria das vezes, o processo de contratação de uma FPSO é realizado através de processo licitatório (no caso de empresas de E\&P públicas) ou processo de tomada de preços (empresas privadas). Existem outras formas de definição do afretador da FPSO, entretanto, a empresa de E\&P tenderá sempre a buscar mais de um possível fornecedor, de forma a incentivar o processo concorrencial e uma taxa diária mais baixa.

No processo competitivo, a empresa de afretamento da FPSO que oferecer a melhor proposta técnica-economica, é a vencedora do contrato e terá a incumbência de operar a FPSO ao longo do período pré-definido.

A proposta técnica dos concorrentes possuem características semelhantes, visto que os componentes da FPSO são fabricados pelos mesmos fornecedores e 
as empresas de afretamento convidadas a participar do processo competitivo possuem capacidade técnica e experiência nesse tipo de negócio.

Como resultado, a definição da taxa diária se torna o ponto chave do processo competitivo, sendo assim, as empresas que conseguirem quantificar a geração de valor da melhor forma possui vantagem no certame. A Figura 4 resume de forma mais clara como o processo competitivo funciona:

\section{Figura 4 - Processo Competitivo - Contratação FPSO}
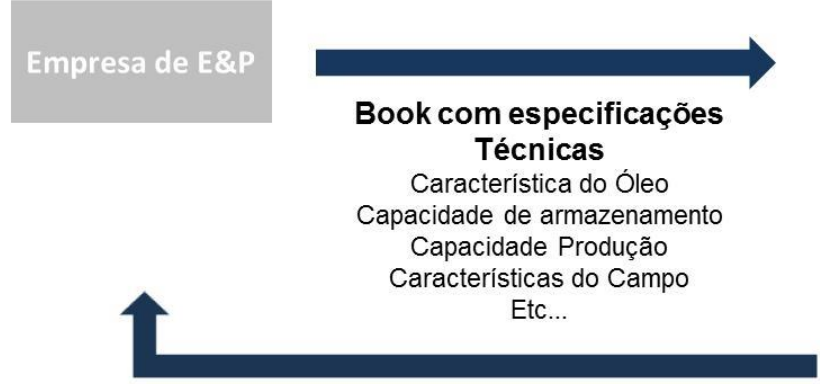

Empresas de Afretamento

Tomada de Preços

Taxa diária Concorrente 1

Taxa diária Concorrente 2

Taxa diária Concorrente 3
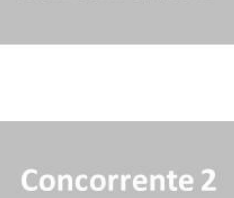

Concorrente 3

\section{Concorrente com menor taxa diária vence o processo}

Fonte: Elaboração Própria 


\section{5 \\ Metodologia Utilizada}

Neste capítulo serão descritas as metodologias utilizadas para a precificação das opções embutidas nos contratos de afretamento de FPSO.

Em um contrato de afretamento, a empresa proprietária da embarcação recebe pelo afretamento e prestação de serviços uma remuneração fixa, no final do período de contrato a empresa pode vender a embarcação.

$\mathrm{Na}$ literatura existem trabalhos que tratam da precificação dos contratos de leasing, conforme descrito na revisão de literatura, entretanto, não foi encontrado um modelo aplicável ao caso de afretamento de FPSOs.

Umas das questões que precisam ser direcionadas antes de definir o modelo a ser utilizado é o processo estocástico que descreve melhor a característica do ativo base. Conforme mostrado, muitos ativos reais podem ser modelados através de MGB, entretanto, em alguns casos, é mais apropriado que a modelagem do processo estocástico seja feita através de MRM.

O cálculo do valor das opções embutidas no contrato será realizado da forma tradicional, calculando inicialmente o valor do contrato sem opção, em seguida, serão precificadas as opções embutidas.

As principais variáveis que impactam o exercício ou não da opção por parte da empresa de E\&P são o preço do petróleo futuro e a quantidade de petróleo disponível no campo. Como o objetivo do trabalho é mostrar como a utilização da teoria de opções reais agrega valor ao processo de definição da taxa diária por parte das empresas de afretamento, as informações acerca da variável de incerteza considerada precisam estar disponíveis a todos os participantes do processo competitivo, sendo assim, a variável utilizada para o cálculo das opções será o preço do petróleo no mercado internacional.

O exercício da opção por parte da empresa de E\&P e consequente recebimento de mais um ano de remuneração pela empresa de afretamento depende do preço do petróleo na data de exercício da opção. 
$\mathrm{Na}$ Figura 5 esse mecanismo fica mais claro. A empresa de afretamento possui um contrato de 1 ano com a empresa de E\&P, que possui a opção de utilizar a embarcação e os serviços de operação por mais um ano, cuja remuneração anual é de $\$ 1.000$. Assumindo que o valor mínimo do preço do petróleo aceitável para que a empresa de E\&P exerça a opção seja de \$90/barril, teríamos o seguinte fluxo.

\section{Figura 5 - Exemplo Exercício da Opção}

Ano 0

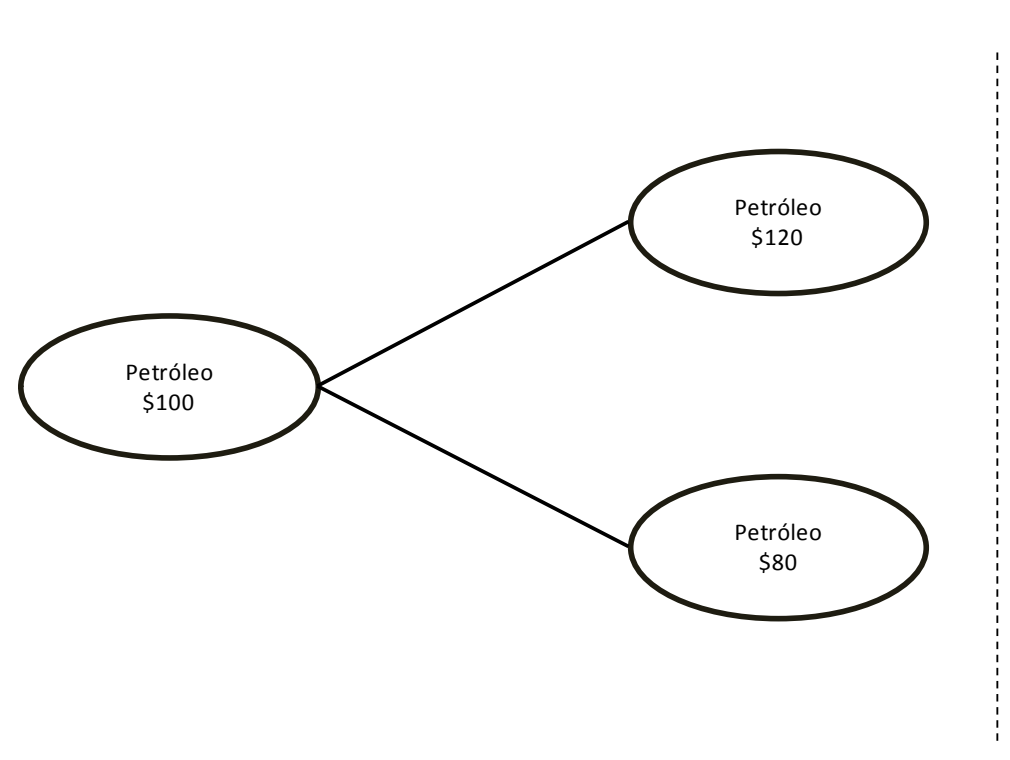

Ano 1
Ano 2

Fluxo Adicional Empresa de Afretamento

Remuneração Adicional $\$ 1.000$

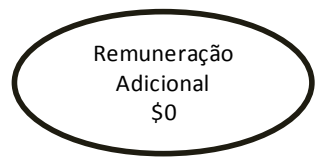

Com o exercício da opção, a empresa de afretamento recebe 1 ano a mais de fluxo de caixa, caso contrário o contrato acabaria. O que podemos representar da seguinte forma:

$$
\operatorname{se}\left(p_{\text {anoexercicio- } 1} \geq p_{\min } ; F C_{\text {ano }} ; 0\right)
$$

Onde:

$P_{\text {anoexercício- } 1}=$ Preço do petróleo no último dia de renovação da opção

$P_{\min }=$ Preço do petróleo mínimo atrativo para a empresa de E\&P.

$F C_{\text {ano }}=$ Fluxo de caixa adicional 
A definição do $P_{\min }$ é subjetiva, dependendo das características dos campos nos quais a empresa de E\&P realiza a exploração. Como exemplo, o preço mínimo que torna a extração de petróleo no pré-sal brasileiro viável é superior ao da exploração no pós-sal.

Além disso, outra variável precisa ser considerada para o cálculo da opção. Como o valor da embarcação decai com o passar do tempo, no cenário onde o exercício da opção é realizado, a empresa de afretamento receberá um valor residual inferior no final do contrato. A indústria utiliza como premissa que o valor perdido pela FPSO em cada ano é igual ao saldo depreciado. Como as embarcações são projetadas considerando um período de vida útil máximo descrito no contrato, essa premissa de perda de valor é coerente.

\section{1.}

\section{Modelo Estocástico}

Para a definição do processo estocástico, é necessário que se utilize uma série histórica para a realização dos testes estatísticos. A série histórica do preço do petróleo tipo Brent (Europa) utilizada foi do período de maio de 1987 a dezembro de 2014, conforme Figura 6:

\section{Figura 6 - Preço Histórico do Petróleo Tipo Brent (Europa)}

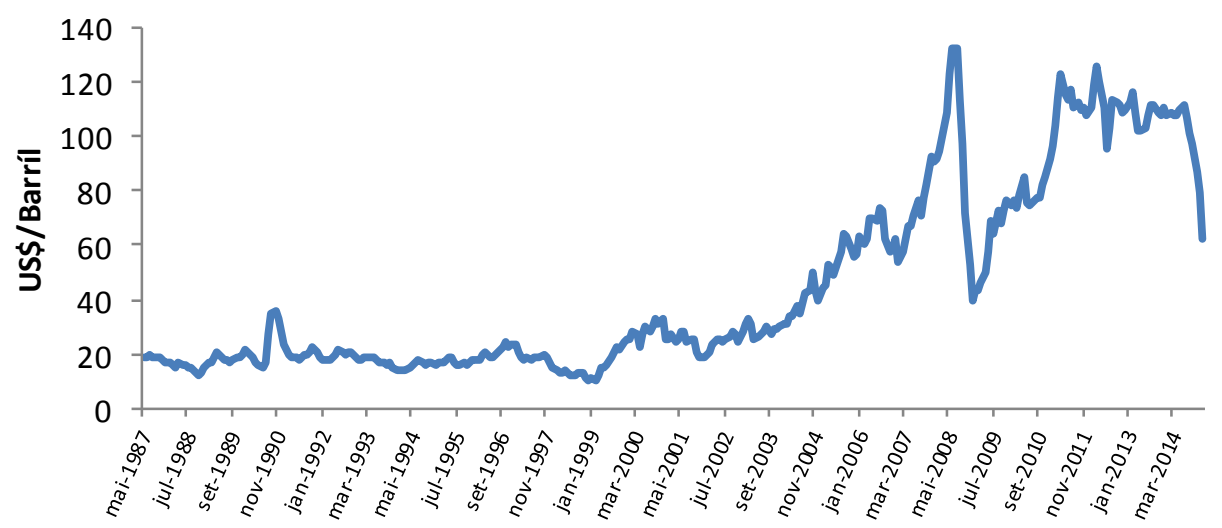

Para a realização do teste de raíz unitária foi utilizado o software Eviews. Na Tabela 3 pode ser visualizado o resultado do teste para a amostra. 
Tabela 3 - Teste de Raíz Unitária (DF)

Hipótese Nula: Brent posui raiz unitária

Exogenous: Constant

Lag Length: 1 (Automatic - based on SIC, maxlag=16)

\begin{tabular}{lrrr}
\hline \hline & & t-Statistic & Prob. $^{*}$ \\
\hline \hline Augmented Dickey-Fuller test statistic & -1.867270 & 0.3477 \\
\hline Test critical values: & 1\% level & -3.449977 & \\
& $5 \%$ level & -2.870084 & \\
& $10 \%$ level & -2.571391 & \\
\hline \hline
\end{tabular}

*MacKinnon (1996) one-sided p-values.

Ao comparar os resultados com os valores críticos, notamos que a hipótese nula de que a série possui raiz unitária não foi rejeitada. Esse resultado converge com a comprovação de Dixit and Pindyck (1994) que os preços do petróleo não seguem um MGB apenas quando a série analisada é superior a 120 anos. Os autores analizaram séries de 30 e 40 anos e não conseguiram rejeitar a hipótese nula. A não rejeição de um caminho aleatório (MGB) ainda pode permitir a existência de algum nível de auto-regressão (reversão à média) na variável estudada (Bastian-Pinto \& Brandao, 2009).

Para a definição do processo estocástico é necessário que se considere as características econômicas além das estatísticas. Nesse sentido, o petróleo tem características cujo preço de equilíbrio depende de oferta e demanda, onde a utilização do MRM é apropriada.

Neste trabalho serão apreentados os resultados da precificação das opções utilizando o MGB, através da árvore CRR, e o MRM, através do modelo censurado de Nelson and Ramaswamy (1990).

\subsection{1.}

\section{Modelagem do Preço do Petróleo através de MGB}

Para a modelagem do preço do petróleo através da árvore binomial CRR, é necessário calcular alguns parâmetros de forma a tornar a árvore recombinante. $\mathrm{O}$ contrato de afretamento será avaliado considerando fluxos de caixa anuais, desta forma, a volatilidade histórica do preço deve ser anual.

O calculo da volatilidade histórica considerou o desvio padrão dos $\log$ retorno da série entre 1987 e 2014, o resultado encontrado foi uma volatilidade de 
30,3\% a.a.. Conforme descrito na revisão de literatura, a volatilidade histórica é utilizada para calcular os parâmetros de subida $\mu$, descida $d$ e probabilidades $p$.

O valor encontrado para essas variáveis é mostrado abaixo:

$$
\begin{aligned}
& \mu=1,35 \\
& d=0,74 \\
& p=0,51
\end{aligned}
$$

O valor base do cálculo da árvore binomial foi o preço do petróleo brent (europa) de US\$ 62,34/barril, valor do mercado spot no último dia de negociação de dezembro de 2014.

A Tabela 4 mostra a árvore binomial do preço do petróleo para os próximos 18 anos.

\begin{tabular}{|c|c|c|c|c|c|c|c|c|c|c|c|c|c|c|c|c|c|c|}
\hline \multicolumn{19}{|c|}{ Preço do Petróleo } \\
\hline 0 & 1 & 2 & 3 & 4 & 5 & 6 & 7 & 8 & 9 & 10 & 11 & 12 & 13 & 14 & 15 & 16 & 17 & 18 \\
\hline \multirow[t]{19}{*}{62} & 84 & 114 & 155 & 209 & 284 & 384 & 520 & 704 & 953 & 1.290 & 1.747 & 2.365 & 3.201 & 4.334 & 5.868 & 7.945 & 10.756 & 14.563 \\
\hline & 46 & 62 & 84 & 114 & 155 & 209 & 284 & 384 & 520 & 704 & 953 & 1.290 & 1.747 & 2.365 & 3.201 & 4.334 & 5.868 & 7.945 \\
\hline & & 34 & 46 & 62 & 84 & 114 & 155 & 209 & 284 & 384 & 520 & 704 & 953 & 1.290 & 1.747 & 2.365 & 3.201 & 4.334 \\
\hline & & & 25 & 34 & 46 & 62 & 84 & 114 & 155 & 209 & 284 & 384 & 520 & 704 & 953 & 1.290 & 1.747 & 2.365 \\
\hline & & & & 19 & 25 & 34 & 46 & 62 & 84 & 114 & 155 & 209 & 284 & 384 & 520 & 704 & 953 & 1.290 \\
\hline & & & & & 14 & 19 & 25 & 34 & 46 & 62 & 84 & 114 & 155 & 209 & 284 & 384 & 520 & 704 \\
\hline & & & & & & 10 & 14 & 19 & 25 & 34 & 46 & 62 & 84 & 114 & 155 & 209 & 284 & 384 \\
\hline & & & & & & & 7 & 10 & 14 & 19 & 25 & 34 & 46 & 62 & 84 & 114 & 155 & 209 \\
\hline & & & & & & & & 6 & 7 & 10 & 14 & 19 & 25 & 34 & 46 & 62 & 84 & 114 \\
\hline & & & & & & & & & 4 & 6 & 7 & 10 & 14 & 19 & 25 & 34 & 46 & 62 \\
\hline & & & & & & & & & & 3 & 4 & 6 & 7 & 10 & 14 & 19 & 25 & 34 \\
\hline & & & & & & & & & & & 2 & 3 & 4 & 6 & 7 & 10 & 14 & 19 \\
\hline & & & & & & & & & & & & 2 & 2 & 3 & 4 & 6 & 7 & 10 \\
\hline & & & & & & & & & & & & & 1 & 2 & 2 & 3 & 4 & 6 \\
\hline & & & & & & & & & & & & & & 1 & 1 & 2 & 2 & 3 \\
\hline & & & & & & & & & & & & & & & 1 & 1 & 1 & 2 \\
\hline & & & & & & & & & & & & & & & & 0 & 1 & 1 \\
\hline & & & & & & & & & & & & & & & & & 0 & 0 \\
\hline & & & & & & & & & & & & & & & & & & 0 \\
\hline
\end{tabular}

Tabela 4 - Modelagem Preço do Petróleo - MGB

\subsection{2.}

\section{Modelagem do Preço do Petróleo através do MRM}

Existem inúmeros modelos de MRM que podem ser utilizados para calcular o valor das opções. Bastian-Pinto (2009) utilizou o modelo de reversão à média censurado de Nelson and Ramaswamy (1990) para a precificação de opções cujo processo estocástico pode ser modelado com MRM. 
Os autores sugerem que a volatilidade seja calculada através da seguinte fórmula:

$$
\sigma=\sigma_{\varepsilon} \sqrt{\frac{2 \log (b)}{\left(b^{2}-1\right) \Delta t}}
$$

Para a modelagem através do MRM, é necessário que se tenha outros parâmetros além da volatilidade, são eles:

$S_{0}=$ valor inicial (em $\left.t=0\right)$ da variável estocástica $S_{t}$

$x_{0}=\ln \left(s_{0}\right)$

$\bar{x}=$ valor da média de longo prazo para o qual $x_{t}=\ln \left(s_{t}\right)$ converge

$\eta=$ parâmetro de velocidade de reversão à média do processo

$\Delta t=$ valor do intervalo de tempo

Para o cálculo das demais variáveis necessárias para o teste, temos $b-1=$ $e^{-\eta \Delta t}-1, \eta=-\ln (b) / \Delta t$ e $\bar{x}=-\frac{a}{(b-1)}$.

Os valores das variáveis obtidos utilzando a série histórica foram:

$\sigma=30,44 \%, \eta=0,135, x_{0}=62,34, \bar{x}=68,35$.

As Tabela 5, 67 mostram a árvore binomial do preço do petróleo para os próximos 18 anos e probabilidades de subida e descida em cada nó, respectivamente: 
Tabela 5 - Modelagem Preço do Petróleo - MRM

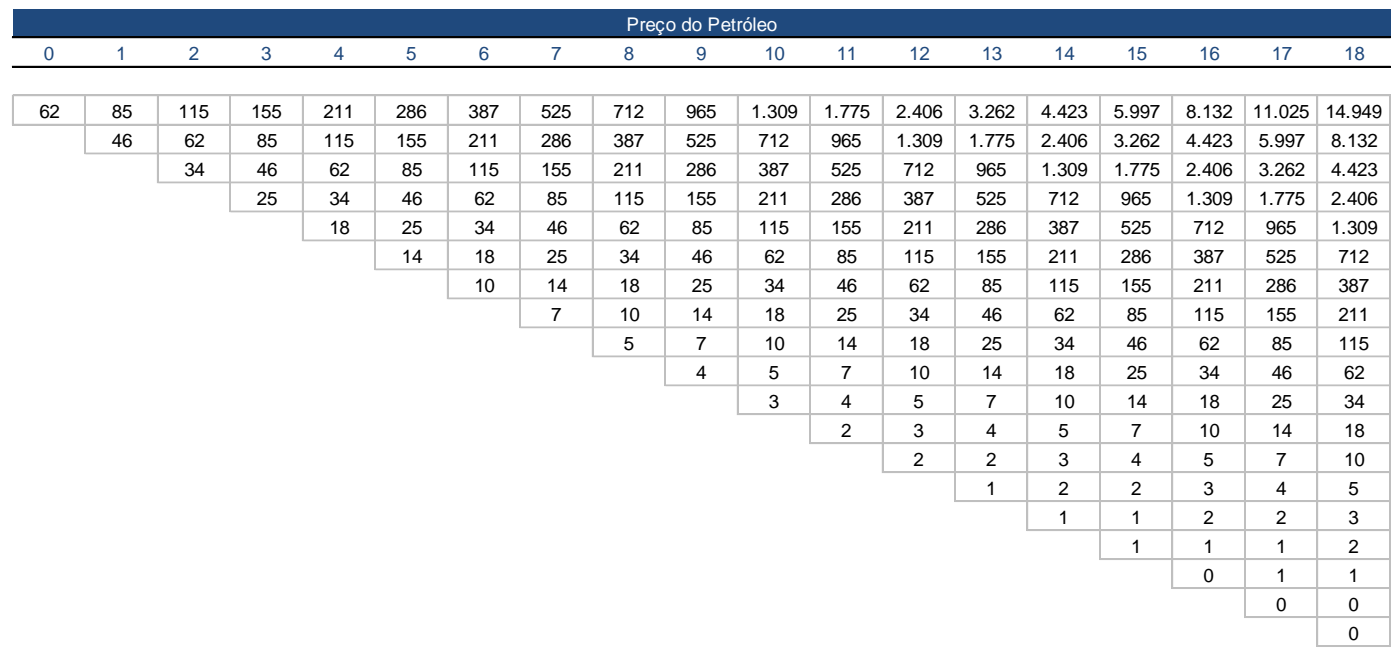

Tabela 6 - Probabilidade de Subida - MRM

\begin{tabular}{|c|c|c|c|c|c|c|c|c|c|c|c|c|c|c|c|c|c|c|}
\hline \multicolumn{19}{|c|}{ Prob Xu } \\
\hline 0 & 1 & 2 & 3 & 4 & 5 & 6 & 7 & 8 & 9 & 10 & 11 & 12 & 13 & 14 & 15 & 16 & 17 & 18 \\
\hline \multirow[t]{19}{*}{$44 \%$} & $38 \%$ & $31 \%$ & $24 \%$ & $17 \%$ & $11 \%$ & $4 \%$ & $0 \%$ & $0 \%$ & $0 \%$ & $0 \%$ & $0 \%$ & $0 \%$ & $0 \%$ & $0 \%$ & $0 \%$ & $0 \%$ & $0 \%$ & $0 \%$ \\
\hline & $51 \%$ & $44 \%$ & $38 \%$ & $31 \%$ & $24 \%$ & $17 \%$ & $11 \%$ & $4 \%$ & $0 \%$ & $0 \%$ & $0 \%$ & $0 \%$ & $0 \%$ & $0 \%$ & $0 \%$ & $0 \%$ & $0 \%$ & $0 \%$ \\
\hline & & $58 \%$ & $51 \%$ & $44 \%$ & $38 \%$ & $31 \%$ & $24 \%$ & $17 \%$ & $11 \%$ & $4 \%$ & $0 \%$ & $0 \%$ & $0 \%$ & $0 \%$ & $0 \%$ & $0 \%$ & $0 \%$ & $0 \%$ \\
\hline & & & $65 \%$ & $58 \%$ & $51 \%$ & $44 \%$ & $38 \%$ & $31 \%$ & $24 \%$ & $17 \%$ & $11 \%$ & $4 \%$ & $0 \%$ & $0 \%$ & $0 \%$ & $0 \%$ & $0 \%$ & $0 \%$ \\
\hline & & & & $71 \%$ & $65 \%$ & $58 \%$ & $51 \%$ & $44 \%$ & $38 \%$ & $31 \%$ & $24 \%$ & $17 \%$ & $11 \%$ & $4 \%$ & $0 \%$ & $0 \%$ & $0 \%$ & $0 \%$ \\
\hline & & & & & $78 \%$ & $71 \%$ & $65 \%$ & $58 \%$ & $51 \%$ & $44 \%$ & $38 \%$ & $31 \%$ & $24 \%$ & $17 \%$ & $11 \%$ & $4 \%$ & $0 \%$ & $0 \%$ \\
\hline & & & & & & $85 \%$ & $78 \%$ & $71 \%$ & $65 \%$ & $58 \%$ & $51 \%$ & $44 \%$ & $38 \%$ & $31 \%$ & $24 \%$ & $17 \%$ & $11 \%$ & $4 \%$ \\
\hline & & & & & & & $92 \%$ & $85 \%$ & $78 \%$ & $71 \%$ & $65 \%$ & $58 \%$ & $51 \%$ & $44 \%$ & $38 \%$ & $31 \%$ & $24 \%$ & $17 \%$ \\
\hline & & & & & & & & $98 \%$ & $92 \%$ & $85 \%$ & $78 \%$ & $71 \%$ & $65 \%$ & $58 \%$ & $51 \%$ & $44 \%$ & $38 \%$ & $31 \%$ \\
\hline & & & & & & & & & $100 \%$ & $98 \%$ & $92 \%$ & $85 \%$ & $78 \%$ & $71 \%$ & $65 \%$ & $58 \%$ & $51 \%$ & $44 \%$ \\
\hline & & & & & & & & & & $100 \%$ & $100 \%$ & $98 \%$ & $92 \%$ & $85 \%$ & $78 \%$ & $71 \%$ & $65 \%$ & $58 \%$ \\
\hline & & & & & & & & & & & $100 \%$ & $100 \%$ & $100 \%$ & $98 \%$ & $92 \%$ & $85 \%$ & $78 \%$ & $71 \%$ \\
\hline & & & & & & & & & & & & $100 \%$ & $100 \%$ & $100 \%$ & $100 \%$ & $98 \%$ & $92 \%$ & $85 \%$ \\
\hline & & & & & & & & & & & & & $100 \%$ & $100 \%$ & $100 \%$ & $100 \%$ & $100 \%$ & $98 \%$ \\
\hline & & & & & & & & & & & & & & $100 \%$ & $100 \%$ & $100 \%$ & $100 \%$ & $100 \%$ \\
\hline & & & & & & & & & & & & & & & $100 \%$ & $100 \%$ & $100 \%$ & $100 \%$ \\
\hline & & & & & & & & & & & & & & & & $100 \%$ & $100 \%$ & $100 \%$ \\
\hline & & & & & & & & & & & & & & & & & $100 \%$ & $100 \%$ \\
\hline & & & & & & & & & & & & & & & & & & $100 \%$ \\
\hline
\end{tabular}

Tabela 7 - Probabilidade de Descida - MRM

\begin{tabular}{|c|c|c|c|c|c|c|c|c|c|c|c|c|c|c|c|c|c|c|}
\hline \multicolumn{19}{|c|}{ Prob Xd } \\
\hline 0 & 1 & 2 & 3 & 4 & 5 & 6 & 7 & 8 & 9 & 10 & 11 & 12 & 13 & 14 & 15 & 16 & 17 & 18 \\
\hline \multirow[t]{19}{*}{$56 \%$} & $62 \%$ & $69 \%$ & $76 \%$ & $83 \%$ & $89 \%$ & $96 \%$ & $100 \%$ & $100 \%$ & $100 \%$ & $100 \%$ & $100 \%$ & $100 \%$ & $100 \%$ & $100 \%$ & $100 \%$ & $100 \%$ & $100 \%$ & $100 \%$ \\
\hline & $49 \%$ & $56 \%$ & $62 \%$ & $69 \%$ & $76 \%$ & $83 \%$ & $89 \%$ & $96 \%$ & $100 \%$ & $100 \%$ & $100 \%$ & $100 \%$ & $100 \%$ & $100 \%$ & $100 \%$ & $100 \%$ & $100 \%$ & $100 \%$ \\
\hline & & $42 \%$ & $49 \%$ & $56 \%$ & $62 \%$ & $69 \%$ & $76 \%$ & $83 \%$ & $89 \%$ & $96 \%$ & $100 \%$ & $100 \%$ & $100 \%$ & $100 \%$ & $100 \%$ & $100 \%$ & $100 \%$ & $100 \%$ \\
\hline & & & $35 \%$ & $42 \%$ & $49 \%$ & $56 \%$ & $62 \%$ & $69 \%$ & $76 \%$ & $83 \%$ & $89 \%$ & $96 \%$ & $100 \%$ & $100 \%$ & $100 \%$ & $100 \%$ & $100 \%$ & $100 \%$ \\
\hline & & & & $29 \%$ & $35 \%$ & $42 \%$ & $49 \%$ & $56 \%$ & $62 \%$ & $69 \%$ & $76 \%$ & $83 \%$ & $89 \%$ & $96 \%$ & $100 \%$ & $100 \%$ & $100 \%$ & $100 \%$ \\
\hline & & & & & $22 \%$ & $29 \%$ & $35 \%$ & $42 \%$ & $49 \%$ & $56 \%$ & $62 \%$ & $69 \%$ & $76 \%$ & $83 \%$ & $89 \%$ & $96 \%$ & $100 \%$ & $100 \%$ \\
\hline & & & & & & $15 \%$ & $22 \%$ & $29 \%$ & $35 \%$ & $42 \%$ & $49 \%$ & $56 \%$ & $62 \%$ & $69 \%$ & $76 \%$ & $83 \%$ & $89 \%$ & $96 \%$ \\
\hline & & & & & & & $8 \%$ & $15 \%$ & $22 \%$ & $29 \%$ & $35 \%$ & $42 \%$ & $49 \%$ & $56 \%$ & $62 \%$ & $69 \%$ & $76 \%$ & $83 \%$ \\
\hline & & & & & & & & $2 \%$ & $8 \%$ & $15 \%$ & $22 \%$ & $29 \%$ & $35 \%$ & $42 \%$ & $49 \%$ & $56 \%$ & $62 \%$ & $69 \%$ \\
\hline & & & & & & & & & $0 \%$ & $2 \%$ & $8 \%$ & $15 \%$ & $22 \%$ & $29 \%$ & $35 \%$ & $42 \%$ & $49 \%$ & $56 \%$ \\
\hline & & & & & & & & & & $0 \%$ & $0 \%$ & $2 \%$ & $8 \%$ & $15 \%$ & $22 \%$ & $29 \%$ & $35 \%$ & $42 \%$ \\
\hline & & & & & & & & & & & $0 \%$ & $0 \%$ & $0 \%$ & $2 \%$ & $8 \%$ & $15 \%$ & $22 \%$ & $29 \%$ \\
\hline & & & & & & & & & & & & $0 \%$ & $0 \%$ & $0 \%$ & $0 \%$ & $2 \%$ & $8 \%$ & $15 \%$ \\
\hline & & & & & & & & & & & & & $0 \%$ & $0 \%$ & $0 \%$ & $0 \%$ & $0 \%$ & $2 \%$ \\
\hline & & & & & & & & & & & & & & $0 \%$ & $0 \%$ & $0 \%$ & $0 \%$ & $0 \%$ \\
\hline & & & & & & & & & & & & & & & $0 \%$ & $0 \%$ & $0 \%$ & $0 \%$ \\
\hline & & & & & & & & & & & & & & & & $0 \%$ & $0 \%$ & $0 \%$ \\
\hline & & & & & & & & & & & & & & & & & $0 \%$ & $0 \%$ \\
\hline & & & & & & & & & & & & & & & & & & $0 \%$ \\
\hline
\end{tabular}




\section{6 Aplicação do modelo em um contrato de afretamento de FPSO}

De forma a analisar como a aplicação da teoria de opções reais influencia a tomada de decisão gerencial nos contratos de afretamento de FPSO, foi examinado um caso hipotético considerando opções de extensão contratual. Para organizar o raciocínio, primeiramente foi realizada a avaliação do projeto utilizando as teorias tradicionais de avaliação de projetos (TIR e VPL). Em seguida, foi utilizada a TOR para precificar as opções embutidas no contrato e verificar de que forma agregam valor à tomada de decisão no processo competitivo.

O fluxo para a definição da taxa diária de afretamento deve ser lido de baixo para cima, de acordo com a Figura 7:

Figura 7- Fluxo de Definição da taxa diária de afretamento

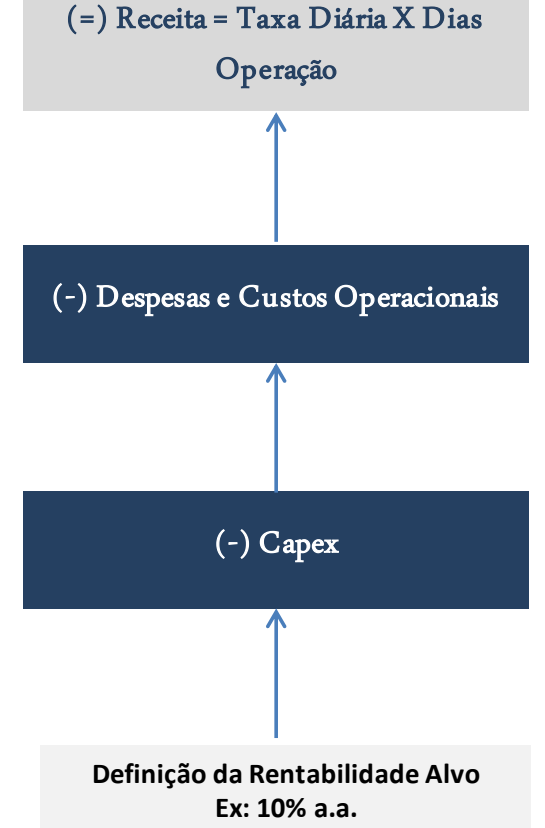


O primeiro passo é definir a rentabilidade alvo considerando os riscos envolvidos na atividade empresarial. Em seguida é estimado o valor do capex total necessário para a construção da embarcação, assim como o cronograma de dispêndio ao longo do tempo. Após isso, são estimados os custos e despesas necessários para a operação da embarcação durante o período contratual.

Depois desse processo, podem ser utilizadas ferramentas de atingir meta para se chegar a taxa diária de afretamento necessária para se obter a rentabilidade desejada considerando todas as premissas descritas.

\section{1.}

Avaliação do Projeto Através das Ferramentas Tradicionais: VPL e TIR

As premissas a seguir foram utilizadas para o cálculo do valor do projeto no cenário estático:

- $\quad$ Período de Contrato -13 anos.

- $\quad$ Período de Construção- 3 anos.

- Período de Operação - 10 anos.

- $\quad$ CapEx da Embarcação - US\$ 1,5 bilhão.

- Deduções da Receita Bruta - 10\% sobre a Receita Bruta.

- $\quad$ OpEx diário - US\$ 100 mil.

- Imposto de Renda-10\%.

- $\quad$ Taxa de depreciação - de 6,7\% ao ano (vida útil projetada para a FPSO -15 anos).

- $\quad$ Valor Residual - equivalente ao valor não depreciado da embarcação. 
Tabela 8 - Fluxo de Caixa Projetado (US\$ Milhões)

\begin{tabular}{|c|c|c|c|c|c|c|c|c|c|c|c|c|c|}
\hline Ano & 1 & 2 & 3 & 4 & 5 & 6 & 7 & 8 & 9 & 10 & 11 & 12 & 13 \\
\hline Receita Bruta & 0 & 0 & 0 & 362 & 362 & 362 & 362 & 362 & 362 & 362 & 362 & 362 & 362 \\
\hline Deduções & 0 & 0 & 0 & (36) & (36) & (36) & (36) & (36) & (36) & (36) & (36) & (36) & (36) \\
\hline Receita Líquida & 0 & 0 & 0 & 325 & 325 & 325 & 325 & 325 & 325 & 325 & 325 & 325 & 325 \\
\hline Custos & 0 & 0 & 0 & (137) & (137) & (137) & (137) & (137) & (137) & (137) & (137) & (137) & (137) \\
\hline Custo de Operação & 0 & 0 & 0 & $(37)$ & (37) & (37) & (37) & $(37)$ & $(37)$ & $(37)$ & (37) & $(37)$ & (37) \\
\hline Depreciação & 0 & 0 & 0 & $(100)$ & $(100)$ & $(100)$ & (100) & $(100)$ & $(100)$ & $(100)$ & $(100)$ & $(100)$ & (100) \\
\hline Lucro Antes dos Imposto: & 0 & 0 & 0 & 189 & 189 & 189 & 189 & 189 & 189 & 189 & 189 & 189 & 189 \\
\hline Impostos & 0 & 0 & 0 & (19) & (19) & (19) & (19) & (19) & (19) & (19) & (19) & (19) & (19) \\
\hline Lucro Líquido & 0 & 0 & 0 & 170 & 170 & 170 & 170 & 170 & 170 & 170 & 170 & 170 & 170 \\
\hline (-) Depreciação & 0 & 0 & 0 & 100 & 100 & 100 & 100 & 100 & 100 & 100 & 100 & 100 & 100 \\
\hline (-) Capex & $(500)$ & $(500)$ & $(500)$ & 0 & 0 & 0 & 0 & 0 & 0 & 0 & 0 & 0 & 0 \\
\hline (+) Valor Residual & 0 & 0 & 0 & 0 & 0 & 0 & 0 & 0 & 0 & 0 & 0 & 0 & 500 \\
\hline Fluxo de Caixa Livre & $(500)$ & $(500)$ & $(500)$ & 270 & 270 & 270 & 270 & 270 & 270 & 270 & 270 & 270 & 770 \\
\hline
\end{tabular}

A taxa diária de US\$ 991 mil foi obtida através da utilização do fluxo descrito na Figura 7, aplicando a ferramenta "atingir meta", fixando como objetivo uma Taxa Interna de Retorno Alvo de 12,0\% a.a.. Desta forma, o VPL do projeto considerando um custo de capital de $10 \%$ foi de US\$ 148,0 milhões.

\section{2.}

\section{Avaliação utilizando Opções Reais}

Uma vez calculado o valor do projeto sem flexibilidade, o próximo passo é calcular o valor considerando as opções embutidas no contrato.

Foi considerado que o contrato base possui 5 opções anuais de extensão de 1 ano cada, ou seja, caso todas as opções sejam exercidas, o período total de operação do contrato será de 15 anos, vida útil da embarcação.

As opções de extensão previstas nos contratos de afretamento concede a empresa de E\&P o direito de utilizar a embarcação e os serviços acordados no contrato por um ano adicional, tendo como custo a taxa de afretamento estabelecida no contrato. Neste trabalho, a opção será analisada sob a ótica da empresa de afretamento, desta forma, é necessário que se estabeleça algumas premissas, são elas:

- Tipo de Opção - a opção precificada neste caso será a opção de extensão contratual detida pela empresa de E\&P, ou seja, no 
momento da contratação, a empresa de E\&P adquire também cinco opções de extensão contratual, ou seja, 5 calls contra o afretador da embarcação.

- Variável de Incerteza - para a empresa de E\&P, o exercício da call está condicionado a basicamente duas variáveis, preço de petróleo e quantidade de petróleo no campo. A modelagem da quantidade de petróleo no campo não é um processo simples, sendo sua execução praticamente impossível pela empresa de afretamento, já a variável preço do petróleo pode ser modelada, pois o ativo é negociado em bolsa e existem dados históricos disponíveis. Nesse sentido, a variável de incerteza considerada neste trabalho será o preço do petróleo. Foi definida de forma arbitrária que o preço mínimo do petróleo necessário para que a empresa de E\&P exerça as opções de extensão contratual seja de U\$ 34,00/barril. Esse valor depende da característica e localização do campo, sendo assim, não é possível definir um valor padrão.

- Taxa livre de risco - foi considerada como premissa uma taxa livre de risco de $5 \%$ ao ano.

$\mathrm{O}$ ano de referência para o exercício da primeira opção de extensão contratual é o ano 13 da Tabela 4 (MGB) e Tabela 5 (MRM), referente ao último ano de operação da FPSO (3 anos de construção + 10 de operação) no contrato sem opção. Nesse sentido, o cálculo do valor da opção é realizado de forma regressiva. Nos cenários da árvore onde o preço do petróleo for igual ou acima de US \$ 34,00/barril, a empresa de E\&P exerce a opção de extensão contratual e a empresa de afretamento recebe um ano a mais de fluxo de caixa de US\$ 270 milhões.

Além disso, como o valor residual da FPSO decresce à medida que os anos passam, é necessário que se subtraia esse valor no cálculo da opção. No cenáro de extensão contratual de um ano, a empresa de afretamento deixa de receber US $\$ 500$ milhões no ano 13 com a venda da embarcação e passa a receber US\$400 milhões no ano 14.

Desta forma, o VPL da perda do valor residual que a empresa de afretamento deixa receber, será subtraído do VPL da Opção. 
Para fins de exemplificação da precificação da opção utilizando MGB, foi calculado o valor presente da opção de extensão contratual de 1 ano.

Primeiramente são inceridos na árvore os fluxos de caixa adicionais que a empresa de afretamento recebe no caso de exercício da opção.

\section{Tabela 9 - Fluxo Adicional - Exercício da Extensão Contratual (1 ano) - MGB}

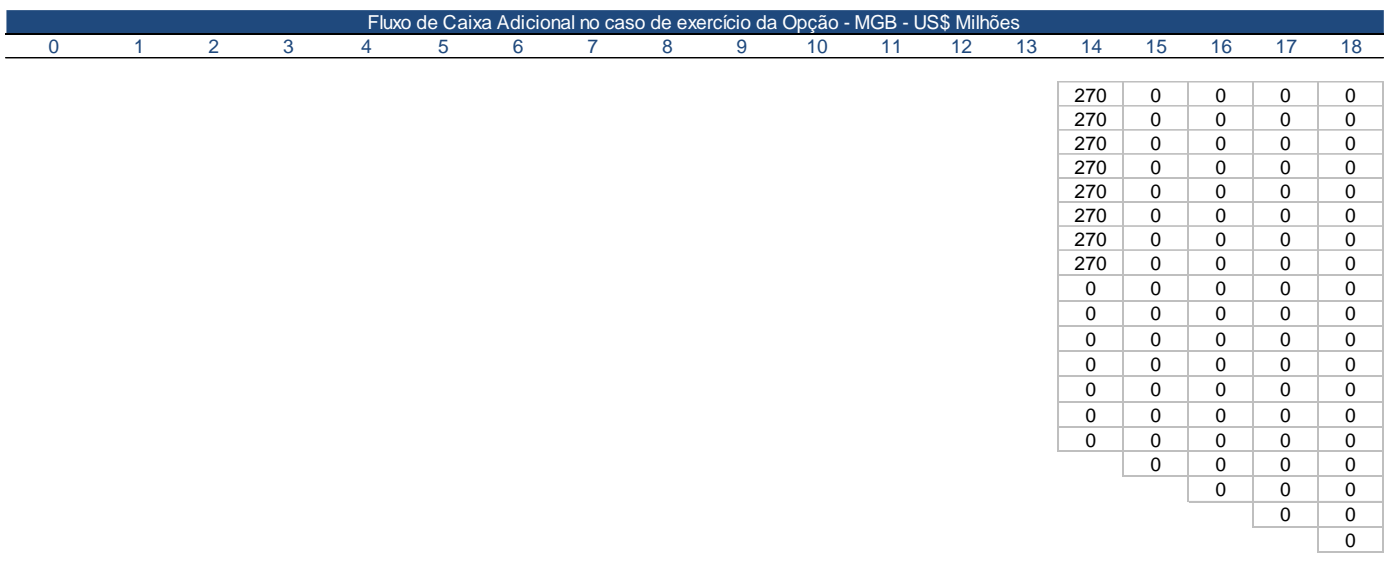

A partir da definição do valor adicional de fluxo de caixa, o valor da opção é calculado de forma recursiva, utilizando os parâmetros encontrados no MGB.

Tabela 10 - Cálculo da Opção de Extensão Contratual (1 ano) - MGB

\begin{tabular}{|c|c|c|c|c|c|c|c|c|c|c|c|c|c|c|c|c|c|c|}
\hline 0 & 1 & 2 & 3 & 4 & 5 & 6 & 7 & 8 & 9 & 10 & 11 & 12 & 13 & 14 & 15 & 16 & 17 & 18 \\
\hline \multirow[t]{17}{*}{85} & 104 & 123 & 141 & 157 & 171 & 182 & 192 & 202 & 212 & 222 & 233 & 245 & 257 & 0 & 0 & 0 & 0 & 0 \\
\hline & 74 & 95 & 117 & 139 & 159 & 177 & 191 & 202 & 212 & 222 & 233 & 245 & 257 & 0 & 0 & 0 & 0 & 0 \\
\hline & & 61 & 82 & 106 & 132 & 158 & 181 & 199 & 212 & 222 & 233 & 245 & 257 & 0 & 0 & 0 & 0 & 0 \\
\hline & & & 46 & 65 & 90 & 119 & 150 & 181 & 205 & 222 & 233 & 245 & 257 & 0 & 0 & 0 & 0 & 0 \\
\hline & & & & 30 & 46 & 69 & 99 & 135 & 174 & 209 & 233 & 245 & 257 & 0 & 0 & 0 & 0 & 0 \\
\hline & & & & & 17 & 28 & 45 & 72 & 108 & 155 & 205 & 245 & 257 & 0 & 0 & 0 & 0 & 0 \\
\hline & & & & & & 7 & 13 & 23 & 41 & 71 & 119 & 185 & 257 & 0 & 0 & 0 & 0 & 0 \\
\hline & & & & & & & 2 & 3 & 7 & 15 & 30 & 63 & 130 & 0 & 0 & 0 & 0 & 0 \\
\hline & & & & & & & & 0 & 0 & 0 & 0 & 0 & 0 & 0 & 0 & 0 & 0 & 0 \\
\hline & & & & & & & & & 0 & 0 & 0 & 0 & 0 & 0 & 0 & 0 & 0 & 0 \\
\hline & & & & & & & & & & 0 & 0 & 0 & 0 & 0 & 0 & 0 & 0 & 0 \\
\hline & & & & & & & & & & & 0 & 0 & 0 & 0 & 0 & 0 & 0 & 0 \\
\hline & & & & & & & & & & & & 0 & 0 & 0 & 0 & 0 & 0 & 0 \\
\hline & & & & & & & & & & & & & 0 & 0 & 0 & 0 & 0 & 0 \\
\hline & & & & & & & & & & & & & & 0 & 0 & 0 & 0 & 0 \\
\hline & & & & & & & & & & & & & & & 0 & 0 & 0 & 0 \\
\hline & & & & & & & & & & & & & & & & 0 & 0 & 0 \\
\hline VP O & & & & 84,90 & & & & & & & & & & & & & 0 & 0 \\
\hline Perda & or Resi & & & 39,50 & & & & & & & & & & & & & & 0 \\
\hline
\end{tabular}

Em seguida, foi calculado o valor presente da perda do valor residual resultando em um valor de US\$ 39,5 milhões, assim, o valor presente líquido da opção encontrado foi de US\$ 45,40 milhões. 
$\mathrm{Na}$ Tabela 1 pode ser visualizado o valor dos fluxos de caixa adicionais que serão exercidos no caso do exercício das 5 opções de extensão contratual.

Tabela 11 - Fluxo Adicional - Exercício da Extensão Contratual (5 anos) - MGB

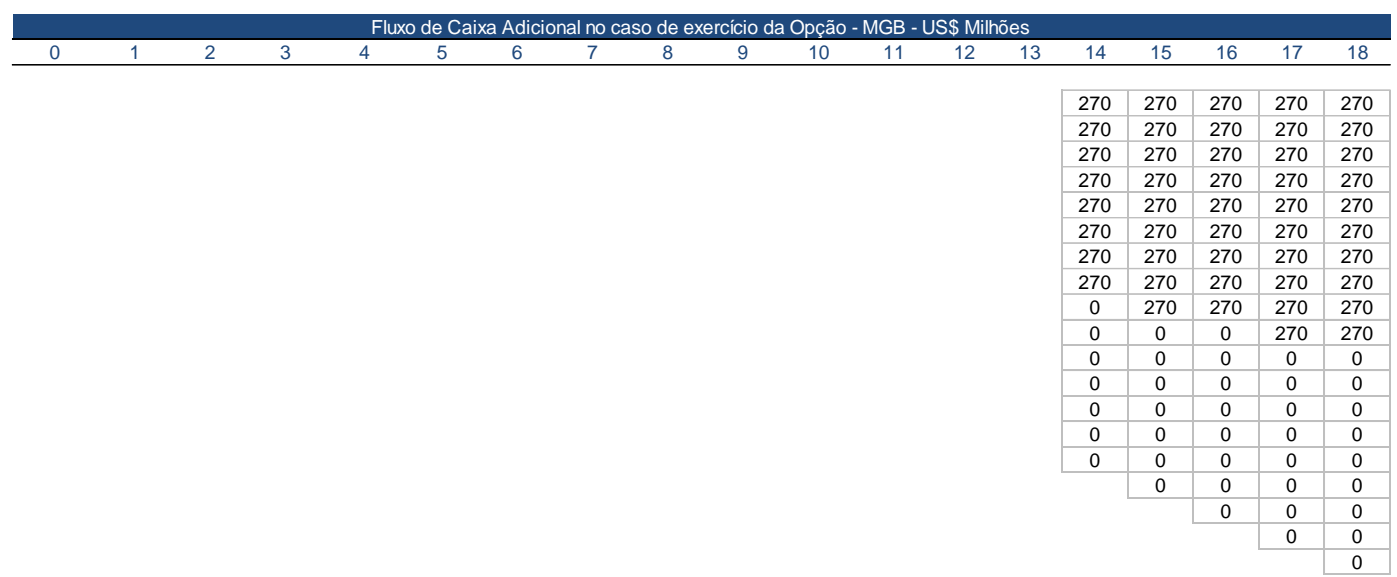

O mesmo cálculo foi feito para as opções de extensão contratual nos anos subsequentes, tanto utilizando MGB quanto MRM.

A Tabela 12 mostra um resumo dos resultados obtidos:

Tabela 12 - Resumo do Valor do Projeto

\begin{tabular}{|c|c|c|c|c|c|}
\hline \multicolumn{6}{|c|}{ Quadro Resumo - Valor do Projeto - US\$̦ Milhões } \\
\hline & US\$ & MGB & MRM & $\begin{array}{l}\text { Diferença } \\
\text { MGB/Base }\end{array}$ & $\begin{array}{c}\text { Diferença } \\
\text { MRM/Base }\end{array}$ \\
\hline VPL Original - Determinístico & 148,04 & 148,04 & 148,04 & & \\
\hline VPL Opção Extensão 1o ano & - & 45,40 & 37,05 & $30,67 \%$ & $25,0 \%$ \\
\hline 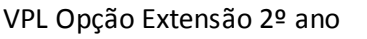 & - & 59,09 & 11,61 & $39,92 \%$ & $7,8 \%$ \\
\hline VPL Opção Extensão 3o ano & - & 48,06 & 40,39 & $32,47 \%$ & $27,3 \%$ \\
\hline VPL Opção Extensão 4ㅇa ano & - & 59,12 & 16,67 & $39,94 \%$ & $11,3 \%$ \\
\hline VPL Opção Extensão 5 ano & - & 48,99 & 42,01 & $33,09 \%$ & $28,4 \%$ \\
\hline VPL Total & 148,04 & 408,70 & 295,76 & $276,08 \%$ & $199,79 \%$ \\
\hline
\end{tabular}

Conforme mostrado na tabela, a precificação das opções de extensão contratual agrega valor significativo ao projeto. No cenário utilizando o MGB, através da árvore CRR, o valor encontrado foi $276,1 \%$ superior ao valor determinístico, já no cenário onde foi utilizado o MRM, o valor encontrado foi $199,8 \%$ superior ao valor original. 
Isso mostra que o projeto possui valor adicional que pode ser capturado ou dividido entre a empresa de afretamento e a empresa de E\&P dependendo da quantidade de empresas particiántes do processo competitivo.

Para fins ilustrativos, o valor determinístico considerou uma taxa diária de afretamento de US\$ 991, com TIR de 12,0\% a.a.. No cenário de precificação das 5 opções de extensão contratual, no MGB teríamos uma TIR de $16,24 \%$ a.a. e $14,2 \%$ a.a. no caso do MRM.

Caso a empresa de afretamento optasse por manter o mesmo patamar de taxa de retorno, poderia ter cobrado uma taxa diária de US\$795 (19,8\% inferior a original), no caso da precificação através de MGB ou US\$880 utilizando MRM (11,2\% inferior a original), conforme Tabela 13.

Tabela 13 - Resumo Taxa Diária

\begin{tabular}{|lccc|}
\hline \multicolumn{4}{|c|}{ Quadro Resumo - Taxas Diárias Oferecidas } \\
\hline & Cenário Base & Cenário MGB & Cenário MRM \\
\hline Taxa diária & USD 990,66 & USD 795,00 & USD 880,00 \\
Desconto sobre a taxa original & & $19,8 \%$ & $11,2 \%$ \\
\hline
\end{tabular}




\section{7 \\ Conclusão}

O objetivo deste trabalho foi mostrar como a utilização de modelos de precificação de opções reais agrega valor ao processo de definição de taxas diárias em processos concorrenciais de afretamento de FPSOs.

A definição do processo estocástico que representa melhor o movimento da variável preço do petróleo pode ser realizada sob duas óticas, uma baseada em testes estatísticos e a outra em características econômicas. Foi utilizado um teste de raiz unitária que não rejeitou a hipótese nula, ou seja, não foi possível rejeitar a hipótese que a série segue um MGB. Sob a ótica econômica, o preço do petróleo apresenta característica cujo preço reverte à média no longo prazo, ou seja, quando os preços estão baixos, o volume dos investimentos diminui o que resulta numa redução da oferta, a mesma lógica acontece quando o preço está acima do nível médio de longo prazo.

Neste trabalho foram precificadas 5 opções de extensão contratual de um ano cada em um contrato de afretamento de FPSO. Os resultados encontrados sugerem que a precificação das opções através de MGB agrega 276,1\% de valor ao contrato original, já na precificação com MRM, o valor encontrado foi 199,8\% superior.

Os resultados do trabalho sugerem que seria possível para o afretador da FPSO oferecer um desconto de 19,8\% (MGB) e 11,2\% (MRM) sob o preço base do contato de afretamento. Esse desconto poderia tornar o afretador mais competitivo no processo concorrencial o que mostra a importância da utilização de ferramentas de precificação de opções nesse tipo de contrato.

Como recomendação para trabalhos futuros, poderiam ser utilizados modelos mais realistas para a modelagem do preço do petróleo, o que tornaria o cálculo da opção mais acurado. Adicionalmente, poderiam ser precificadas opções de compra da embarcação por parte da empresa de E\&P, esse tipo de opção também é comum em contratos de afretamento de FPSO. 


\section{8 \\ Referências Bibliográficas}

Bastian-Pinto, C. (2009). Modelagem de Opções Reais com Processos de Reversão à Média em Tempo Discreto: Uma Aplicação na Indústria Brasileira de Etanol. Tese de Doutorado, Pontifícia Universidade Católica Rio de Janeiro.

Bastian-Pinto, C., \& Brandao, L. (2009). Modelando Opções de Conversão com Movimento de Reversão à Média. In A. C. F. Pinto \& L. F. J. Motta (Eds.), Decisões de Investimento (pp. 279-307). Rio de Janeiro: Mauad X.

Bastian-Pinto, C., \& Brandão, L. (2007). Modelando Opções de Conversão com Movimento de Reversão à Média. RBFin - Revista Brasileira de Finanças, 5(2), 97-124.

Bastian-Pinto, C., Brandão, L., \& Alves, M. L. (2010). Valuing the switching flexibility of the ethanol-gas flex fuel car. Annals of Operations Research, 176(1), 333-348. doi: 10.1007/s10479-009-0514-7

Brealey, R., Myers, S., \& Allen, F. (2011). Principles of Corporate Finance (10th ed.). New York, NY: McGraw-Hill/Irwin.

Brooks, C. (2008). Introductory Econometrics for Finance C. University (Ed.) (pp. 641).

Catherine, G. H. (2011). Analysis of Options in FPSO Leasing Contracts. [Thesis]. (INSTITUTD' ADMINISTRATION DES ENTREPRISES DE PARIS).

Cox, J. C., Ross, S. A., \& Rubinstein, M. (1979). Option pricing: A simplified approach. Journal of Financial Economics, 7(3), 229-263. doi: Doi: $10.1016 / 0304-405 \times(79) 90015-1$

Damodaran, A. (2002). Investment valuation : tools and techniques for determining the value of any asset (2nd ed.). New York: Wiley.

Dias, M. A. (2005). Opções Reais Híbridas com Aplicações em Petróleo. PUCRio, Rio de Janeiro.

Dickey, D., \& Fuller, W. (1981). Likelihood ratio statistics for autoregressive time series with a unit root. . Econometrica, 49, 1057-1072.

Dixit, A. K., \& Pindyck, R. S. (1994). Investment under Uncertainty. Princeton: Princeton University Press. 
Duarte, R. A. d. A. (2012). Pricing of Real Options with Fixed Dividends Dissertação de Mestrado, Pontifícia Universidade Católica do Rio de Janeiro PUC-Rio Rio de Janeiro.

Geske, R., \& Johnson, H. E. (1984). The American Put Option Valued Analytically. The Journal of Finance, 39(5), 1511-1524. doi: 10.2307/2327741

Gitman, L. J. (1997). Princípios de administração financeira: São Paulo: Harbra.

Lombardo, L. (2003). Overview of Floating Production, Storage and Offtake (FPSO) Services Agreements. Australian Resources \& Energy.

Merton, R. C. (1973). Theory of Rational Option Pricing. The Bell Journal of Economics and Management Science, 4(1), 141-183.

Myers, S. C., Dill, D. A., \& Bautista, A. J. (1976). Valuation of Financial Lease Contracts. The Journal of Finance, 31(3), 799-819. doi: 10.2307/2326426

Nelson, D. B., \& Ramaswamy, K. (1990). Simple Binomial Processes as Diffusion Approximations in Financial Models. Review of Financial Studies, 3(3), 393-430.

Roll, R. (1977). An analytic valuation formula for unprotected American call options on stocks with known dividends. Journal of Financial Economics, 5(2), 251-258. doi: http://dx.doi.org/10.1016/0304-405X(77)90021-6

Rouzaut, N., \& Favennec, J.-P. (2011) Petróleo \& gás natural: como produzir e a que custo. ( $2^{\mathrm{a}}$ ed.): Synergia Editora.

Schroder, M. (1988). Adapting the Binomial Model to Value Options on Assets with Fixed-Cash Payouts. Financial Analysts Journal, 9.

Trigeorgis, L. (1996). Evaluating leases with complex operating options. European Journal of Operational Research, 91(2), 315-329. doi: http://dx.doi.org/10.1016/0377-2217(95)00288-X 